\title{
ESPÉCIE INVASORA EM RESERVAS NATURAIS: CARACTERIZAÇÃO DA POPULAÇÃO DE ACHATINA FULICA BOWDICH, 1822 (MOLLUSCA - ACHATINIDAE) NA ILHA RASA, GUARAQUEÇABA, PARANÁ, BRASIL.
}

\author{
Marta Luciane Fischer ${ }^{1}$ \& Eduardo Colley ${ }^{2}$
}

Biota Neotropica v5(n1) - http://www.biotaneotropica.org.br/v5n1/pt/abstract?article+BN03305012005

\author{
Recebido em 13/10/04 \\ Recebida em 31/01/05 \\ Publicado em 07/03/05
}

\author{
${ }^{1}$ Pontifícia Universidade Católica do Paraná - Núcleo de Estudos do Comportamento Animal. \\ Rua Imaculada Conceição, 1155 CEP 80215-901. Curitiba/PR. \\ E-mail: marta.fischer@pucpr.br; nephilla@terra.com.br \\ ${ }^{2}$ Graduando do Curso de Biologia PUCPR - Núcleo de Estudos do Comportamento Animal. Bolsita PIBIC/PUCPR \\ E-mail: eduardocolley@yahoo.com.br
}

\begin{abstract}
The African snail Achatina fulica is one of the 100 most harmfull invasive alien species, causing serious damages mainly in islands. We had as objective to characterize the population of A. fulica in Ilha Rasa, Guaraqueçaba, Paraná, Brazil. Seasonal and diurnal collections of A. fulica and associated fauna were driven in the border and interior forest, sandbank, swamp and urban area of Almeida and Ilha Rasa communities. We collected 959 snails, with an average of 66.4 animals for inspected place, being considered that there is around 9,000 snails in the island. However the frequency of the animals was conditioned the time of the year, size of the animal and community. The small and recent population of $A$. fulica associated to the anthropic environment demands an urgent and effective plan of eradication avoiding its establishment and the dispersion for the wild areas.
\end{abstract}

Key words: Giant african snail, island ecology, biologic invasion, Atlantic forest

\section{Resumo}

O caramujo africano Achatina fulica é uma das cem espécies invasoras do mundo, causando sérios danos principalmente em ilhas. Objetivou-se caracterizar a população de A. fulica na Ilha Rasa, Guaraqueçaba, PR, Brasil. Coletas sazonais diurnas da $A$. fulica e fauna associada foram conduzidas na borda e interior de floresta, restinga, mangue e área urbana das comunidades de Almeida e Rasa. Foram coletados 959 caramujos, com uma média de 66,4 animais vivos por terreno vistoriado, estimando-se que haja em torno de 9.000 caramujos na ilha. No entanto a freqüência dos animais esteve condicionada a época do ano, tamanho do animal e comunidade. A pequena e recente população de $A$. fulica associada ao ambiente antrópico demanda um plano de erradicação urgente e eficaz evitando o seu estabelecimento e a dispersão para as áreas nativas.

Palavras-chave: Caramujo africano, ecologia de ilhas, invasão biológica, floresta atlântica 


\section{Introdução}

O caramujo africano Achatina fulica configura na lista das 100 principais espécies invasoras do mundo (Alowe et al., 2004), uma vez que foi introduzido em diferentes países apresentando uma extraordinária adaptação e dispersão (Teles et al. 1997). O sucesso da espécie relacionado com seu hábito generalista, alta resistência a variáveis ambientais e o elevado potencial reprodutivo favoreceu a proliferação nos pontos de introdução (Raut \& Barker 2002).

A espécie $A$. fulica é originária da África, ocorre de Natal e Moçambique no sul do Kenya à Somália italiana ao norte. Diferente de outras espécies do gênero que se originaram em florestas tropicais úmidas no leste da África ou em florestas temperadas de altas altitudes, A. fulica faz parte das espécies que se diferenciaram no oeste e centro africano, principalmente nas margens das florestas (Raut \& Barker 2002). Provavelmente a necessidade de estratégias adaptativas nesse ambiente instável favoreceu o seu hábito generalista.

A elevada população do molusco africano tem despertado a atenção dos cientistas, da sociedade e das autoridades que vêem na espécie exótica um potencial competidor dos moluscos nativos, praga na agricultura e um possível hospedeiro intermediário de um nematódeo que pode causar meningoencefalite eosinofilica e angiostrongilíase abdominal no homem. Os relatos de ocorrência de $A$. fulica e estudos ecológicos se distribuem por todo o mundo (Raut \& Barker 2002). Casos mais drásticos são registrados nas ilhas como Samoa (Cowie \& Robinson 2003), Chichi-jima (Tomiyama 2000) e Havaí (Cowie 1998), por se constituírem sistemas teoricamente isolados e mais fechados do que os continentes favorecendo a especiação, abrigando grupos endêmicos que ficam vulneráveis frente à competição com uma espécie maior e de hábitos mais generalistas, bem como diante dos métodos de controle (Civeyrel \& Simberloff 1996, Cowie 1998, 2001).

No Brasil o caramujo A. fulica se encontra disseminado por 23 estados englobando diferentes ecossistemas (Teles et al. 1997, Vasconcellos \& Pile 2001, Teles \& Fontes 2002). Atualmente no Estado do Paraná, provavelmente o ponto inicial de introdução da espécie no Brasil, o caramujo está presente em todo o litoral e em inúmeros municípios do interior (Kosloski \& Fischer 2002; Simião 2003). O litoral paranaense é caracterizado por apresentar várias ilhas que compõe um dos últimos remanescentes da Floresta Atlântica brasileira. Neste cenário, $A$. fulica foi introduzida em várias comunidades como uma alternativa rápida e barata de retorno financeiro. No entanto, a criação artesanal e o desinteresse pela carne fizeram com que os produtores abandonassem os caramujos que se espalharam pelas ilhas (Fischer dado não publicado).

Atualmente há uma grande preocupação principalmente por parte de órgãos governamentais em se conhecer a extensão do problema em todo o Brasil. O conhecimento dos habitats preferenciais e distribuição em diferentes biomas são os primeiros passos para o embasamento de programas de manejo, controle e de educação ambiental permitindo, assim, que sejam tomadas medidas direcionadas.

O presente estudo parte da premissa que a análise dos fatores bióticos e abióticos que favoreceram a ocorrência da espécie exótica e as interações intra e interespecíficas registradas em um ecossistema insular servirão como subsídios imediatos tanto para a avaliação ambiental quanto para a tomada de medidas profiláticas e preventivas para outras regiões. E assim, fornecer subsídios para elaboração de protocolos de diagnósticos locais e a determinação de planos de manejo direcionados. Desta forma, objetivou-se caracterizar a população de A. fulica na Ilha Rasa, Guaraqueçaba, Paraná, Brasil, uma das menores ilhas que fazem parte da baía de Guaraqueçaba e representa uma das áreas de proteção ambiental de maior área contínua de Floresta Atlântica do país (SPVS 1999).

\section{Material e Métodos \\ Área de Estudo}

A Ilha Rasa $\left(25^{\circ} 15^{\prime}\right.$ e $25^{\circ} 30^{\prime}$ S e $48^{\circ} 20^{\prime}$ e $48^{\circ} 30^{\prime}$ O) está localizada na porção norte do Estado do Paraná, fazendo parte da Área de Proteção Ambiental de Guaraqueçaba. Com uma área de aproximadamente $10,5 \mathrm{Km}^{2}$ e altitude máxima de $40 \mathrm{~m}$, é caracterizada como uma planície arenosa integrante dos cordões litorâneos, formada por sedimentos de origem continental marinha, principalmente de idade Quaternária. A cobertura vegetal original é composta por três unidades fitoecológicas: formações pioneiras de influência fluviomarinha (mangue e campos salinos), formação pioneira de influência marinha (restinga) e floresta ombrófila densa. Atualmente residem na ilha cerca de 430 habitantes, cujas principais atividades são pesca, a pesca artesanal do caranguejo, a criação de mariscos e a coleta de moluscos marinhos. Os moradores da ilha são distribuídos em quatro comunidades: Ponta do Lanço, Mariana, Almeida e Ilha Rasa (SPVS 1999).

\section{Método de amostragem}

O estudo da distribuição da A. fulica foi conduzido na borda e interior de mata, mangue, restinga e área urbana. Nos quatro primeiros (biomas naturais) foi delimitado aleatoriamente um quadrante de $25 \mathrm{~m}^{2}$. O caramujo exótico e seus vestígios (fezes e conchas vazias) foram procurados em toda a área, vistoriando embaixo de troncos caídos, entre raízes, na vegetação (até uma altura de aproximadamente $2 \mathrm{~m}$ ), entre a serrapilheira e sob uma camada de $5 \mathrm{~cm}$ de solo. Em cada estação do ano, foram realizadas duas coletas em cada habitat, totalizando 32 amostras e $800 \mathrm{~m}^{2}$ de área vistoriada. 
As coletas na área urbana foram realizadas em Almeida e em Ilha Rasa (PR). Foram utilizados dois métodos de amostragem. No primeiro, foram coletados todos os moluscos e posturas presentes em um substrato durante 30 min e no segundo, um ambiente foi vistoriado por $30 \mathrm{~min}$, mas foram despendidos no máximo 10 min em cada substrato, sendo registrados todos os substratos presentes contando ou não com a presença do caramujo. Para cada estação do ano foram procedidas quatro vistorias no ambiente urbano, totalizando 16 amostras e $8 \mathrm{~h}$ de busca ativa.

As coletas foram diurnas e caracterizaram o "sítio de repouso" da A. fulica. Á medida que os indivíduos foram coletados, as dimensões da concha foram tomadas com o paquímetro e a distância do molusco mais próximo com uma trena. Os animais coletados foram imediatamente fixados em álcool $90^{\circ} \mathrm{Gl}$, a fim de minimizar o tempo de permanência do animal em condição estressante e impedir o início da decomposição da glândula digestiva o que impediria a visualização do ovotestis e conseqüentemente a determinação da idade e estágio reprodutivo. Os animais mensurados foram categorizados em pequenos (até $3 \mathrm{~cm}$ de concha), médios ( $3,1 \mathrm{a} 5,0 \mathrm{~cm}$ ) e grandes $(5,1 \mathrm{~cm})$, baseados na presença de gônada.

As plantas utilizadas por $A$. fulica como alimento e/ ou sítio de repouso (Tabela 2), o solo dos locais avaliados e a fauna associada (Tabela 3) foram amostrados para caracterização do sítio de ocorrência.

O material testemunho de A. fulica e dos táxons dos Filos Platyhelminthes, Annelida, Arthropoda foram tombados no Museu de Zoologia da Pontifícia Universidade Católica do Paraná e o material testemunho dos táxons do Filo Mollusca Laboratório de Malacologia - Universidade Federal do Rio de Janeiro - Museu Nacional - Departamento de Invertebrados.

\section{Análise etinoecológica}

O questionário etinoecológico semi-estruturado foi aplicado a 30 moradores abordados aleatoriamente nas comunidades de Almeida e Ilha Rasa. Foram elaboradas questões sócio-econômicas objetivando definir o universo da amostra e questões relacionadas ao histórico e a biologia do caramujo na ilha, para analisar o conhecimento dos ilhéus em relação a $A$. fulica, enriquecer as informações sobre a ocorrência do caramujo na ilha e automaticamente subsidiar ações de manejo que envolvam a sensibilização da comunidade.

\section{Análise das ovotestis}

O registro do desenvolvimento do aparelho reprodutor e as medidas da concha foram baseados em Tomyama (1993). Os dados foram relativos a 90 animais coletados em cada estação do ano. Foram retirados da amostra coletada 10 indivíduos de cada classe de tamanho: menor do que $4 \mathrm{~cm} ; 4,1-4,5 ; 4,6-5,5,1-5,5,5,6-6 ; 6,1-6,5 ; 6,6-$ $7,7,1-8$, maior 8,0 . Nas conchas foram contadas o número de voltas e mensurado a altura da espira, largura da abertura, espessura do perístoma e medido o comprimento da columela (Fig. 8); e do sistema reprodutor foram registradas a presença do ovotestis, as áreas da glândula de albume e próstata e bursa copulatrix e tomado o comprimento do pênis. As estruturas do aparelho reprodutor foram medidas seguindo as ilustrações e descrições de Tomyama (1993) para A. fulica. Para delimitação do pênis foi considerado o final do átrio e o início do músculo retrator do pênis (Fig. 8). Ressalva-se que essa região se destacava das demais estruturas, não sendo utilizado o ducto eferente como referência para delimitação. Para tomada de medidas o aparelho reprodutor era distendido sob uma superfície plana, sem forçar a mudança da forma da estrutura. Nos indivíduos que apresentaram útero com retenção de ovos, os mesmos foram quantificados.

\section{Procedimento estatístico}

Para as análises dos dados de freqüência foi utilizado o teste Qui-quadrado, enquanto que para os dados paramétricos utilizaram-se os testes ANOVA e Teste $t$ de Student e para os não paramétricos, os testes Kruskall-Wallis (H) e Mann-Whitney (U).

As respostas obtidas na análise etinoecológica foram comparadas com o teste do Qui-quadrado, sendo apresentados no texto apenas as respostas significativas $(\mathrm{P}<0,05)$.

\section{RESULTADOS}

\section{Caracterização das comunidades}

Achatina fulica ocorreu em duas comunidades da Ilha Rasa: Almeida e Ilha Rasa. Ambas comunidades não dispõem de coleta municipal de lixo e não há nenhum projeto de reciclagem. O destino do lixo produzido fica sob responsabilidade de cada morador, que o deposita próximo de casa para queimar, enterrar ou descarta na floresta, mangue, restinga ou mar. No entanto, a maior parte do lixo é descartada próximo das casas, em baixo das bananeiras ou do pau-d'água e sapateira utilizadas como cercas-vivas.

A comunidade de Almeida apresenta o maior número de construções antrópicas e de moradores da Ilha, aproximadamente 90 casas, oito igrejas e quatro comércios, os quais segundo SPVS (1999), compõe aproximadamente 350 moradores, representados por 135 homens, 145 mulheres e 70 crianças. Grande parte dos terrenos contém plantas alimentícias e ornamentais, nativas e exóticas (Tabela 2). A maioria das espécies exóticas é representada pela bananeira e duas espécies ornamentais: pau-d'água e a sapateira, introduzidas na ilha para serem utilizadas como cercas-vivas. Pelo menos 30 terrenos dispõem de grande quantidade de cercas-vivas. 
O limite territorial da comunidade de Ilha Rasa é feito pelo mar, pela restinga e uma parte pela floresta. A comunidade comporta cerca de 69 construções e apenas cinco delas são rodeadas por cercas-viva, onde também são utilizados o pau-d'água e a sapateira. Os terrenos são caracterizados pela ausência de delimitações. O solo de Ilha Rasa é arenoso, apresentando baixa retenção de água e baixo teor de material orgânico depositado (Tabela 1). Em Ilha Rasa existem apenas duas casas de comércio e uma igreja, os quais, segundo SPVS (1999) para aproximadamente 150 pessoas, sendo 43 homens, 55 mulheres e 52 crianças.

Cada comunidade apresenta peculiaridades na sua estrutura social. Na Ilha Rasa, a organização social é baseada nas relações de parentesco, o líder religioso também representa a liderança comunitária. Essa estrutura permite que o convívio seja mantido sem a necessidade de construção de limites nos terrenos, evitando, assim a utilização de plantas exóticas como cercas-vivas. Já na comunidade de Almeida, além da igreja católica há mais de uma igreja evangélica, havendo aparentemente, criação de grupos sociais distintos. A imposição de certos procedimentos sociais pelas igrejas favorece que os moradores se isolem, cercando seus terrenos.

\section{Caracterização da população de $A$. fulica}

As vistorias sazonais resultaram na coleta de 959 caramujos cuja freqüência não foi a mesma nas quatro estações do ano $\left(\chi_{(3)}^{2}=42 ; \mathrm{P}<0,01\right)$, sendo coletados mais caramujos na primavera e no outono (Figura 1).

Foi coletada uma média de 66,4 $\pm 45,5$ A. fulica viva $(\mathrm{N}=16$; i.v. $=0-180)$ por terreno vistoriado. Considerando o total de terrenos $(\mathrm{N}=136)$, estima-se que haja em torno de 9.000 animais na ilha. Os caramujos apresentaram um tamanho médio de $5,2 \pm 2,1 \mathrm{~cm}(\mathrm{~N}=1077$; i.v. $=0,5-12)$, havendo diferença entre as estações do ano (ANOVA: $\mathrm{F}=$ 12,$3 ; \mathrm{P}<0,01 ; \mathrm{gl}=3$ ), sendo que o tamanho dos indivíduos coletados durante a primavera foi significativamente maior do que nas demais estações, enquanto que no inverno os animais foram significativamente menores (Figura 2).

A freqüência de animais coletados diferiu conforme a comunidade, havendo significativamente mais caramujos em Almeida $(\mathrm{N}=665)$ do que em Ilha Rasa $(\mathrm{N}=412)\left(\chi_{(1)}^{2}=\right.$ 59; $\mathrm{P}<0,01)$.

O espaçamento médio entre os caramujos foi de 29,8 $\pm 58,9 \mathrm{~cm}(\mathrm{~N}=726$; i.v. $=0-600)$ e diferiu em cada estação do ano $(\mathrm{ANOVAF}=27,5 ; \mathrm{P}<0,01 ; \mathrm{gl}=3)$. No verão, inverno e na primavera os indivíduos estavam mais próximos, enquanto no outono os indivíduos estiveram mais afastados (Figura 3).

A altura média registrada durante as coletas foi de 43,6 $\pm 66,5 \mathrm{~cm}(\mathrm{~N}=1077$; i.v. $=0$-500), porém ocorreram diferenças nas quatro estações do ano (ANOVAF $=13,7 ; \mathrm{P}<0,01 ; \mathrm{gl}=3$ ). A primavera foi a estação em que os caramujos foram registrados mais próximos do solo, enquanto no outono e inverno foram registradas as maiores alturas (Figura 4).

$\mathrm{O}$ registro da atividade de $A$. fulica na ilha evidenciou que o molusco permaneceu em repouso durante o dia na maior parte do ano, porém no inverno a maioria dos caramujos estava em estivação $\left(\chi_{(2)}^{2}=1200 ; \mathrm{P}<0,01\right)$ (Figura 5). No entanto, não foi verificada relação entre a atividade com o tamanho do caramujo e comunidade que foram coletados, predominando o repouso em todas as classes de tamanho (grandes: $\chi_{(2)}^{2}=926$; $<<0,01$; médios: $\chi_{(2)}^{2}=322 ; \mathrm{P}<0,01$ e pequenos: $\left.\chi_{(2)}^{2}=182 ; \mathrm{P}<0,01\right)$ e em ambas comunidades $\left(\chi_{(2)}^{2}=1427 ; \mathrm{P}<0,01\right)$.

\section{Caracterização do "sítio de repouso"}

Os locais onde A. fulica foi coletada caracterizou o seu sítio de repouso, os quais foram separados em quatro categorias: base das plantas, plantas, superfícies orgânicas e superfícies antrópicas. A base das plantas e as plantas foram os locais preferidos $\left(\chi_{(3)}^{2}=231 ; \mathrm{P}<0,01\right)$ (Fig. 6).

O local de ocorrência da $A$. fulica diferiu nas quatro estações do ano, sendo que a ocorrência nas plantas foi preferencial em todas as estações $\left(\chi_{(3)}^{2}=49 ; \mathrm{P}<0,01\right)$. No inverno e primavera houve registro significativo de $A$. fulica também na base das plantas $\left(\chi_{(3)}^{2}=84 ; \mathrm{P}<0,01\right.$; $\left.\chi_{(3)}^{2}=87 ; \mathrm{P}<0,01\right)$ e no outono em superfícies orgânicas $\left(\chi_{(3)}^{2}=67 ; \mathrm{P}<0,01\right)$.

O local de ocorrência de $A$. fulica também diferiu conforme o tamanho do caramujo, sendo que grandes $\left(\chi_{(3)}^{2}\right.$ $=349 ; \mathrm{P}<0,01)$ e médios $\left(\chi_{(3)}^{2}=23 ; \mathrm{P}<0,01\right)$ ocorreram mais nas plantas e os pequenos nas superfícies orgânicas $\left(\chi_{(3)}^{2}=\right.$ 29; $\mathrm{P}<0,01)$.

O local de ocorrência de $A$. fulica também diferiu nas comunidades, sendo que em Almeida foram coletados mais moluscos na base das plantas e nas plantas $\left(\chi_{(3)}^{2}=344\right.$; $\mathrm{P}<0,01)$ enquanto em Ilha Rasa o molusco predominou nas superfícies antrópicas e nas plantas $\left(\chi_{(3)}^{2}=19 ; \mathrm{P}<0,01\right)$.

\section{Planta como "sítio de repouso"}

O caramujo A. fulica foi registrado em 24 espécies de plantas (Tabela 2), ocorrendo mais nos vegetais exóticos ( $\mathrm{N}$ $=368)$ do que nos nativos $(\mathrm{N}=73)\left(\chi_{(14)}^{2}=506 ; \mathrm{P}<0,01\right)$, predominando no pau-d'água, sapateira e bananeira $\left(\chi_{(8)}^{2}=\right.$ 446; $\mathrm{P}<0,01)$.

Comparando a ocorrência de A. fulica em plantas alimentícias e ornamentais houve predomínio nas ornamentais, principalmente na sapateira $\left(\chi_{(1)}^{2}=160\right.$; $\left.\mathrm{P}<0,01\right)$. Nas alimentícias o caramujo predominou na bananeira (planta: $\chi_{(5)}^{2}=413$; $\mathrm{P}<0,01$; base das plantas: $\chi_{(3)}^{2}=31$; $\mathrm{P}<0,01$ ), enquanto nas ornamentais o predomínio ocorreu no pau-d'água (planta: $\chi_{(9)}^{2}=571 ; \mathrm{P}<0,01$ ) e sapateira (base das plantas: $\left.\chi_{(4)}^{2}=599 ; \mathrm{P}<0,01\right)$. 
A ocorrência do caramujo nas plantas e base das plantas não diferiu nas comunidades, sendo que o predomínio do molusco nas plantas se deu no pau-d'água e bananeira tanto em Almeida $\left(\chi_{(16)}^{2}=250 ; \mathrm{P}<0,01\right)$ quanto na Ilha Rasa $\left(\chi_{(7)}^{2}=24 ; \mathrm{P}<0,01\right)$ e na base das plantas o predomínio foi na sapateira (Almeida: $\chi_{(8)}^{2}=320 ; \mathrm{P}<0,01 \mathrm{e}$ Ilha Rasa: $\left.\chi_{(2)}^{2}=16 ; \mathrm{P}<0,01\right)$.

Nas plantas, o caramujo pode ocorrer na base das plantas ( $\mathrm{N}=262)$, no caule $(\mathrm{N}=233)$, na folha $(\mathrm{N}=196)$ ou no fruto $(\mathrm{N}=9)$ (Fig. 6). Foi registrada maior ocorrência na base e no caule $\left(\chi_{(3)}^{2}=222 ; \mathrm{P}<0,01\right)$.

$\mathrm{Na}$ avaliação quantitativa da ocorrência de $A$. fulica nas bananeiras, em 30 plantas foram coletados 452 moluscos, sendo uma média de $13,5 \pm 13,6$ animais $(\mathrm{N}=30$; i.v. $=1-47)$ por planta. Considerando as diferentes partes da árvore em que foram coletados (folhas, caule ou base) houve diferença na freqüência dos moluscos $\left(\chi_{(2)}^{2}=10,7\right.$; $\mathrm{P}<0,01$ ), predominando no caule (Fig. 7). Não houve correlação entre o diâmetro das bananeiras e número total de moluscos.

A localização específica do caramujo nas plantas variou conforme a estação do ano. Durante o inverno foi mais freqüente na base das plantas $\left(\chi_{(2)}^{2}=19 ; \mathrm{P}<0,01\right)$, no outono no caule $\left(\chi_{(2)}^{2}=127 ; \mathrm{P}<0,01\right)$, na primavera houve ocorrência em fruto, porém o predomínio se deu na base $\left(\chi_{(3)}^{2}=96 ; \mathrm{P}<0,01\right)$ e durante $\mathrm{o}$ verão na base $\left(\chi_{(2)}^{2}=18 ; \mathrm{P}<0,01\right)$.

A localização específica variou com o tamanho do caramujo, os grandes ocorreram mais no caule e na base das plantas $\left(\chi_{(3)}^{2}=164 ; \mathrm{P}<0,01\right)$, enquanto médios $\left(\chi^{2}(3)=\right.$ $50 ; \mathrm{P}<0,01)$ e pequenos $\left(\chi^{2}(3)=78 ; \mathrm{P}<0,01\right)$ apenas na base das plantas.

A localização específica variou em cada comunidade, em Almeida houve maior ocorrência nas folhas e base das plantas $\left(\chi_{(3)}^{2}=171 ; \mathrm{P}<0,01\right)$, enquanto em Ilha Rasa apenas no cavle $\left(\chi_{(3)}^{2}=83 ; \mathrm{P}<0,01\right)$.

\section{Base das plantas como "sítio de repouso"}

$\mathrm{O}$ acúmulo de resíduos naturais e antrópicos embaixo das plantas, como as bananeiras e cercas-vivas proporciona a A. fulica diferentes locais de repouso. Os caramujos ocorreram na base de nove espécies de plantas: samambaia $(\mathrm{N}=2)$, limoeiro $(\mathrm{N}=4)$, sombreiro $(\mathrm{N}=6)$, cana-de-açúcar $(\mathrm{N}=8)$, maracujá $(\mathrm{N}=14)$, vegetação secundária de restinga $(\mathrm{N}=23)$, bananeira $(\mathrm{N}=32)$, pau-d'água $(\mathrm{N}=40)$ e sapateira $(\mathrm{N}=226)$, predominando na sapateira $\left(\chi_{(8)}^{2}=1027 ; \mathrm{P}<0,01\right)$. Os caramujos ocorreram em diferentes substratos presentes na base das plantas, como: folhas $(\mathrm{N}=3)$, pedras $(\mathrm{N}=4)$, tijolos $(\mathrm{N}=10)$, lixo orgânico ( $\mathrm{N}=57)$ e solo $(\mathrm{N}=192)$ (Fig. 6), predominando no solo $\left(\chi_{(4)}^{2}=490 ; \mathrm{P}<0,01\right)$, principalmente junto às raízes das $\operatorname{plantas}\left(\chi_{(5)}^{2}=497 ; \mathrm{P}<0,01\right)$.

$\mathrm{O}$ registro do caramujo nos diferentes substratos presentes na base das plantas diferiu com as estações do ano.
No inverno e no verão o predomínio foi no solo $\left(\chi_{(3)}^{2}=83\right.$; $\left.\mathrm{P}<0,01 ; \chi_{(1)}^{2}=49 ; \mathrm{P}<0,01\right)$, enquanto no outono e na primavera não houve diferença. Porém, não diferiu com o tamanho do animal, sendo que em todas as classes o predomínio foi no solo (grandes: $\chi_{(3)}^{2}=283 ; \mathrm{P}<0,01$; médios: $\chi_{(3)}^{2}=82 ; \mathrm{P}<0,01$; pequenos: $\chi_{(2)}^{2}=87$; $\left.\mathrm{P}<0,01\right)$ nem entre as comunidades, evidenciando a preferência de $A$. fulica pelo solo em ambas (Almeida: $\chi_{(4)}^{2}=243 ; \mathrm{P}<0,01$; Ilha Rasa: $\chi_{(3)}^{2}=111 ; \mathrm{P}<0,01$ ).

\section{Superfícies orgânicas como "sítio de repouso"}

As superfícies orgânicas onde exemplares de $A$. fulica foi registrada foram: solo espodossolo cárbico (areia) $(\mathrm{N}=$ 1), composteira $(\mathrm{N}=20)$, vegetação secundária de restinga $(\mathrm{N}=7)$, conchas de ostra $(\mathrm{N}=14)$, solo $(\mathrm{N}=9)$ e serrapilheira $(\mathrm{N}=107)$ (Fig. 6), havendo predomínio na serrapilheira $\left(\chi_{(5)}^{2}\right.$ $=358 ; \mathrm{P}<0,01)$.

$\mathrm{O}$ caramujo africano predominou enterrado em superfícies orgânicas nas quatro estações do ano $\left(\chi_{(1)}^{2}=\right.$ 134; $\mathrm{P}<0,01$ ), nas três classes de tamanho (grandes: $\chi_{(1)}^{2}=$ 29; $\mathrm{P}<0,01$; médios: $\chi_{(1)}^{2}=52 ; \mathrm{P}<0,01$ e pequenos: $\chi_{(1)}^{2}=51$; $\mathrm{P}<0,01$ ) e nas duas comunidades (Almeida: $\chi_{(3)}^{2}=84 ; \mathrm{P}<0,01$; Ilha Rasa: $\left.\chi_{(3)}^{2}=84 ; \mathrm{P}<0,01\right)$.

\section{Superfícies antrópicas como "sítio de repouso"}

Os caramujos ocorreram em diferentes superfícies antrópicas, como casas e resto de materiais de construções, sendo registrados na base da construção $(\mathrm{N}=11)$, na face inferior de um substrato $(\mathrm{N}=57)$ ou na face superior $(\mathrm{N}=$ 78) (Fig. 6), predominando na superior $\left(\chi_{(2)}^{2}=48 ; \mathrm{P}<0,01\right)$.

As superfícies antrópicas utilizadas por $A$. fulica foram: casa $(\mathrm{N}=16)$, cerca $(\mathrm{N}=4)$, entulho $(\mathrm{N}=55)$, lixo inorgânico $(\mathrm{N}=26)$, madeira $(\mathrm{N}=7)$, pedras $(\mathrm{N}=6)$, poste $(\mathrm{N}$ $=1)$, telhas $(\mathrm{N}=57)$, tijolos $(\mathrm{N}=6)$ e vaso $(\mathrm{N}=1)$ (Fig. 6).

As superfícies antrópicas que os caramujos mais utilizaram durante $\mathrm{o}$ ano foram telhas e entulhos $\left(\chi^{2}{ }_{(9)}=225\right.$; $\mathrm{P}<0,01)$. A ocorrência do caramujo nos diferentes substratos variou entre as estações do ano, sendo que no inverno o predomínio ocorreu nas telhas $\left(\chi_{(2)}^{2}=62 ; \mathrm{P}<0,01\right)$, no outono no lixo $\left(\chi_{(3)}^{2}=135 ; \mathrm{P}<0,01\right)$ e na primavera no entulho $\left(\chi_{(4)}^{2}\right.$ $=55 ; \mathrm{P}<0,01)$. Houve variação também com o tamanho do animal, sendo que os grandes predominaram nas telhas e no lixo $\left(\chi_{(9)}^{2}=121 ; \mathrm{P}<0,01\right)$, os médios nas telhas e no entulho $\left(\chi_{(6)}^{2}=225 ; \mathrm{P}<0,01\right)$ e os pequenos predominaram no entulho $\left(\chi_{(5)}^{2}=17 ; \mathrm{P}<0,01\right)$ e com as comunidades, sendo que em Almeida a maioria ocorreu no lixo $\left(\chi_{(9)}^{2}=33 ; \mathrm{P}<0,01\right) \mathrm{e} \mathrm{em}$ Ilha Rasa em entulhos e telhas $\left(\chi_{(3)}^{2}=89 ; \mathrm{P}<0,01\right)$.

\section{Fauna associada ao "sítio de repouso"}

A fauna associada ao sítio de repouso de $A$. fulica foi composta por quatro filos de invertebrados incluído em diferentes táxons (Tabela 3). Os indivíduos de A. fulica 
encontrados na superfície dos substratos apresentaram associação somente com co-específicos, enquanto os indivíduos coletados sob os substratos no sítio de repouso evidenciaram associação com animais de outros grupos.

Dentre os moluscos, se destacou a espécie endêmica Megalobulimus parafragilior Leme \& Indrusiak, 1990, ameaçada de extinção (MMA 2003). Foram registrados indivíduos vivos $(\mathrm{N}=7)$, principalmente na base de plantas frutíferas, e os mortos $(\mathrm{N}=5)$, em locais que os moradores utilizam para queimar lixo e $A$. fulica.

Foi registrada interação trófica entre as planárias terrestres e $A$. fulica, sendo observada mais de uma vez a planária consumindo o caramujo.

\section{Macroanatomia do sistema reprodutor}

O caramujo A. fulica apresenta gônada hermafrodita (ovostestis), no entanto algumas estruturas são exclusivamente masculinas ou femininas enquanto outras são compartilhadas apesar de locais internos onde se deslocam as células sexuais, espermatóforos e ovos, fecundados ou não, externamente aparentam desempenhar as mesmas funções. Fig $8 \mathrm{a}, \mathrm{b}, \mathrm{c}$ )

A parte masculina do sistema reprodutor é representada pela próstata (massa lobulada justaposta ao longo do útero), ducto deferente (ligação entre a próstata e o complexo peniano) (Fig. 8 a, b, c).

A parte feminina é composta pela glândula de albume (lobulada, geralmente apresenta-se grande no animal adulto, esbranquiçada, com material gelatinoso (reserva alimentar para o embrião), útero (armazena os ovos fecundados, após a formação da casca, pela glândula responsável por este envoltório), oviduto (estrutura que liga o útero à vagina), bursa copulatrix (conhecida também como espermateca ou receptáculo seminal, armazena a massa de esperma recebida durante a cópula) e a vagina tubo curto que se abre no àtrio, que possui duas aberturas, a do complexo peniano na lateral e a do poro genital na distal) (Fig. 8 a, b, c).

As estruturas que fazem parte da porção hermafrodita são: a glândula hermafrodita ou ovotestis (glândula produtora de espermatozóides e óvulos), ducto hermafrodita (conexão entre a glândula hermafrodita e o complexo fecundação), complexo fecundação (local de encontro entre os espermatozóides recebidos durante a cópula e os óvulos produzidos) e átrio e poro genital (orifício circular único aberto para o exterior, localizado do lado direito da região cefálica) (Fig. 8 a, b, c).

Os valores médios das estruturas da concha e do aparelho reprodutor e a relação entre as duas estão dispostos no anexo 1.

O número médio de ovos encontrados no útero foi de $96 \pm 46(\mathrm{~N}=12 ;$ i.v. $=60-203)$; de conchas que apresentaram tamanho médio de $7 \pm 1,5 \mathrm{~cm}(\mathrm{~N}=12$; i.v. $=3,4-9,4)$; do perístoma de $0,45 \pm 0,14 \mathrm{~cm}(\mathrm{~N}=12 ; 0,3-0,7)$ e do pênis de 1,2 $\pm 0,3 \mathrm{~cm}(\mathrm{~N}=12$, i.v. $=0,9-1,9)$ e área média da glândula de albume de $0,4 \pm 0,12 \mathrm{~cm}^{2}(\mathrm{~N}=12 ;$ i.v. $=0,2-0,57)$ (conforme o tempo de vida ou ciclo sexual) e próstata de $2 \pm 1 \mathrm{~cm}^{2}(\mathrm{~N}=$ $12 ;$ i.v. $=1,5-2,8)$.

Oviposições de $A$. fulica foram encontradas em todas as estações do ano. Na primavera foram registradas duas posturas (dez ovos), no verão uma postura (50 ovos). No outono foram registradas duas posturas (50 ovos que não eclodiram e 130 ovos depositados recentemente), enquanto no inverno foi registrada apenas uma postura (cerca de 50 ovos).

As posturas ocorreram enterradas até $10 \mathrm{~cm}$ de profundidade e espalhadas sobre o substrato, sendo registradas no solo, junto à base das plantas e em demais substratos utilizados como sítio de repouso. Os ovos de $A$. fulica também foram encontrados dentro de conchas de caramujos mortos com a massa corporal decomposta.

\section{Análise Etinoecológica}

A entrevista nas comunidades correspondeu a $43 \%$ em Ilha Rasa e 57\% em Almeida, sendo a maioria dos entrevistados homens (70\%) que cursaram até o primário $(56,7 \%)$ e apresentavam idade média de $34,5 \pm 16,5$ anos $(\mathrm{N}$ $=30$; i.v. $=11-65)$. Entre os homens $87 \%$ eram nativos, os que não haviam nascido no local, estavam na ilha a mais de 40 anos. A profissão predominante foi a de pescador (50\%) e só um não tinha casa própria.

A avaliação dos terrenos indicou que a maioria significativa estava limpo $(76,7 \%)$ e a manutenção era feita mensalmente $(53,3 \%)$. Não houve diferenças no número de casas que apresentava ou não entulho e composteira, porém prevaleceu a ausência de hortas $(76,7 \%)$, plantas $(80 \%)$ e umidade $(66,7 \%)$. A maioria das casas estava localizada próxima ao mar $(56,7 \%)$.

Somente um dos entrevistados disse não conhecer o caramujo exótico, enquanto que $73,3 \%$ disseram conhecer também o $M$. parafragilior, quando questionado sobre o caramujo nativo denominado de caracol, caramujo, caramujo rosa ou escambul. Quando mostrada a concha dos dois caramujos $86,7 \%$ distinguiu a diferença entre as espécies.

Apesar de $70 \%$ dos entrevistados dizer que $A$. fulica ocorre em seus quintais, somente $70 \%$ perceberam aumento nos últimos anos, porém não souberam dizer a quanto tempo começou. A maioria dos entrevistados disse não ter visto-a em outros lugares $(63,3 \%)$, sendo que $50 \%$ disseram não saber onde elas ocorrem.

Segundo os entrevistados, A. fulica ocorre em plantas $(\mathrm{N}=2)$, casas $(\mathrm{N}=1)$, lixo $(\mathrm{N}=7)$, lugar úmido $(\mathrm{N}=3)$, mato $(\mathrm{N}=2)$ e não souberam responder $(\mathrm{N}=15)$. A maioria afirma que o caramujo está na ilha há um ano $(66,7 \%)$, sendo que $63,3 \%$ não sabe como foi parar na ilha, os que sabem dizem que foi uma moradora quem levou. 


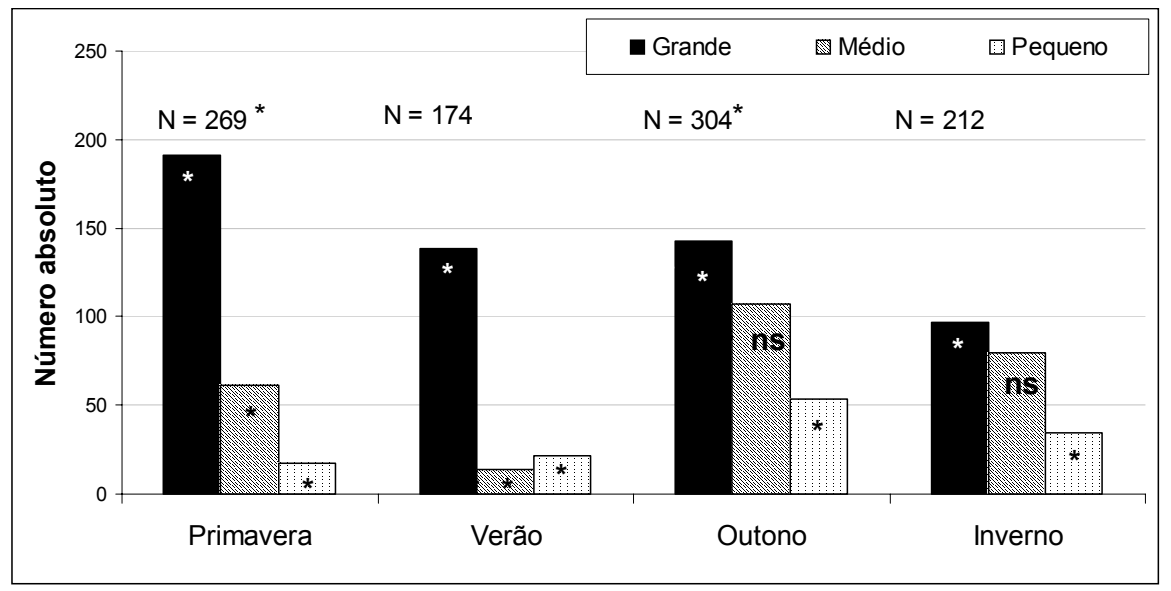

Figura 1. Número absoluto de exemplares de A. fulica grandes, médios e pequenos coletados em cada estação do ano. Os valores foram comparados através do teste do Qui-quadrado, sendo os valores significativos $(P<0,05)$ representados pelo asterisco $(*)$ e os não significativos representados por " $n s$ ".

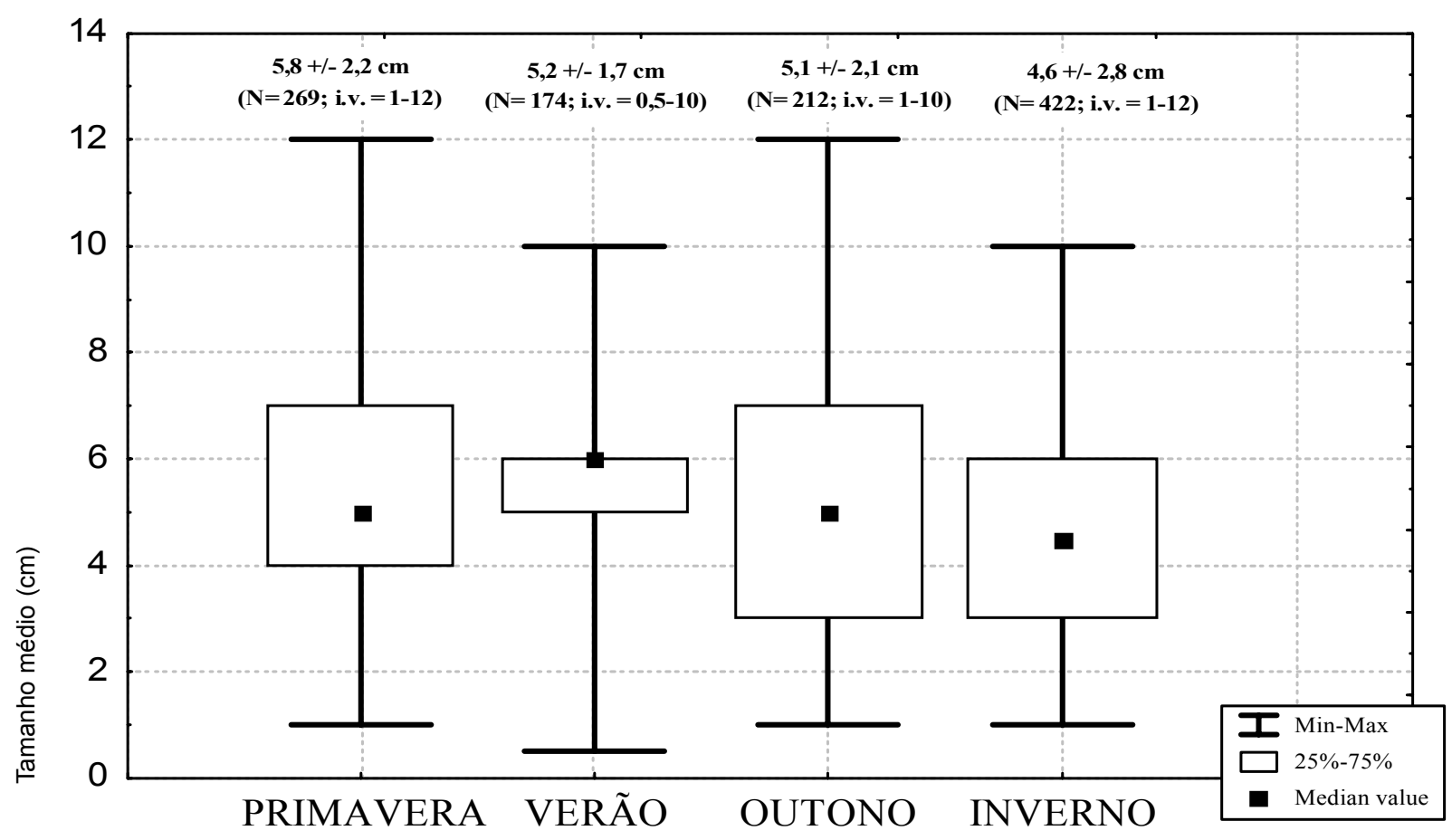

Figura 2. Tamanho médio de exemplares de A. fulica nas quatro estações do ano. 


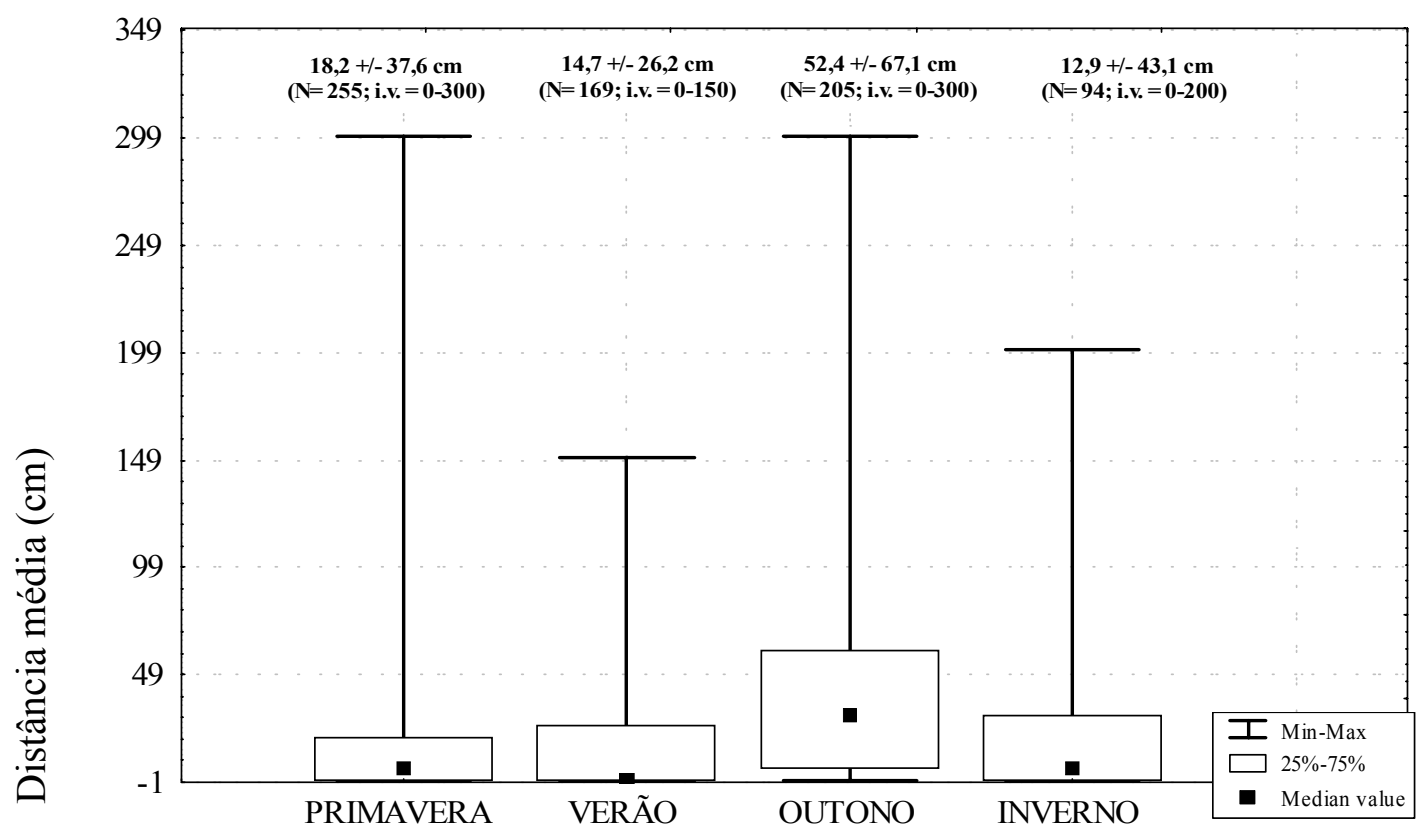

Figura 3. Espaçamento médio entre indivíduos de A. fulica nas quatro estações do ano.

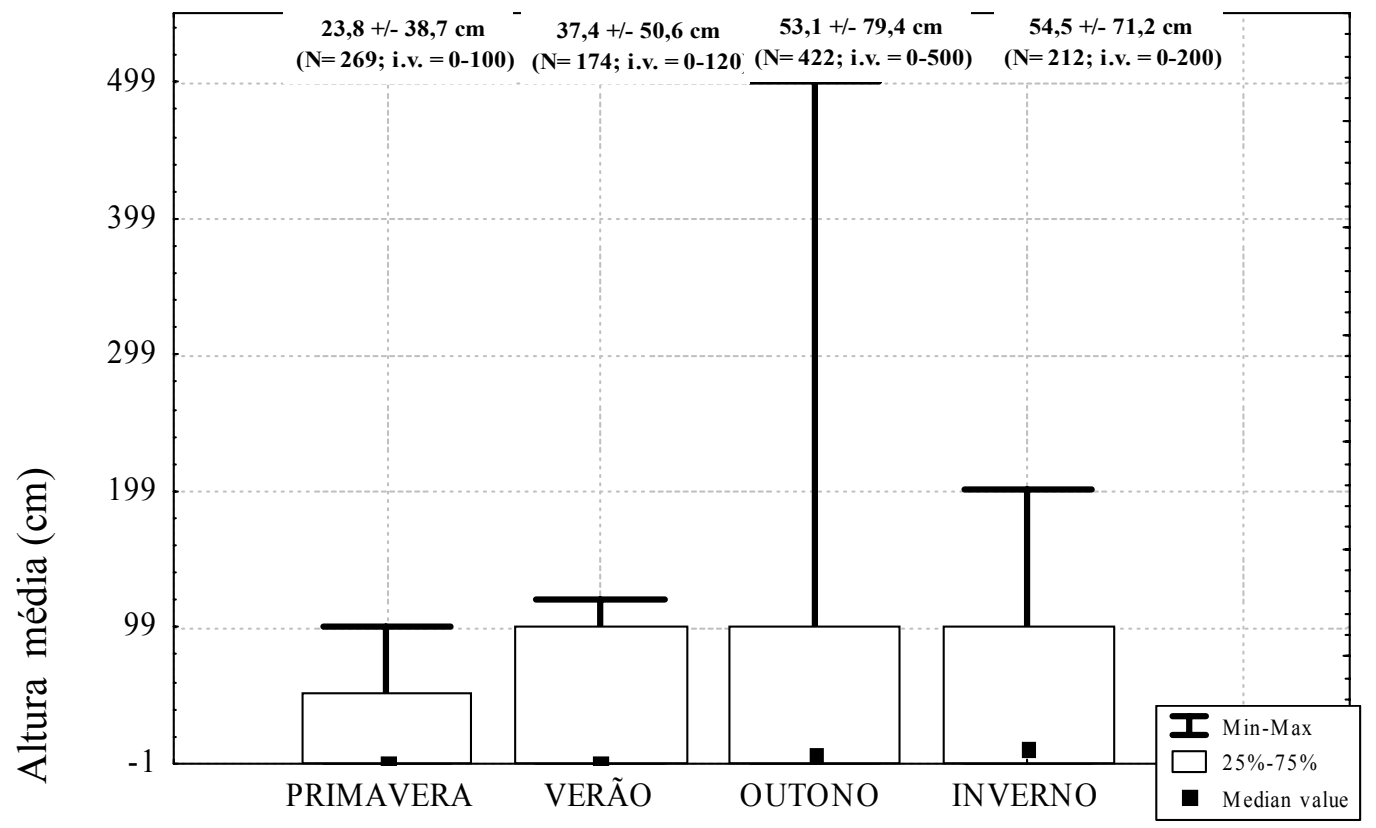

Figura 4. Altura média de exemplares de A. fulica nas quatro estações do ano. 


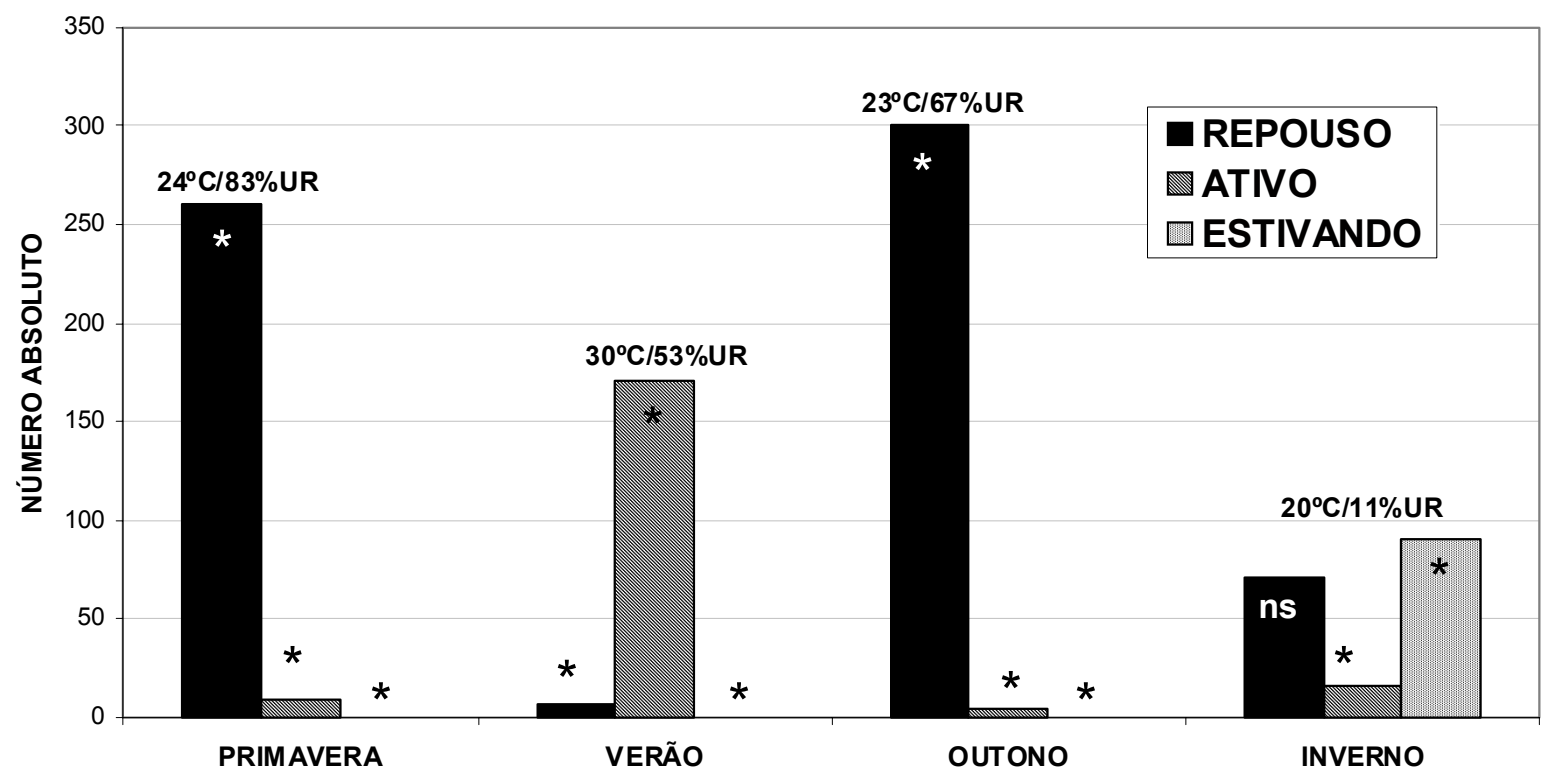

Figura 5. Número absoluto de A. fulica em atividade, repouso e estivação. Os valores foram comparados através do teste do Qui-quadrado, sendo os valores significativos $(P<0,05)$ representados pelo asterisco $(*)$ e os não significativos representados por " $n$ s".
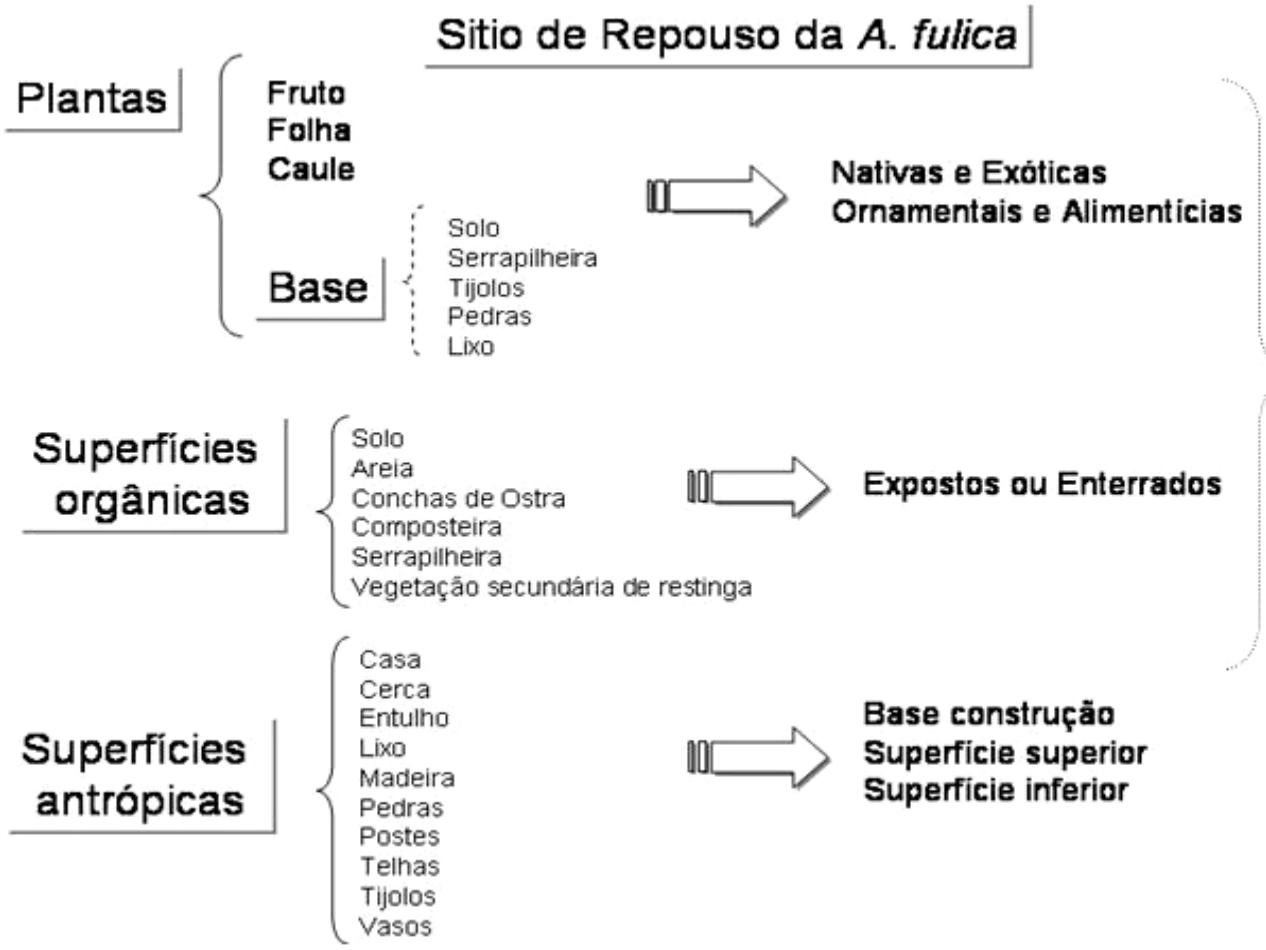

\section{Variáveis}
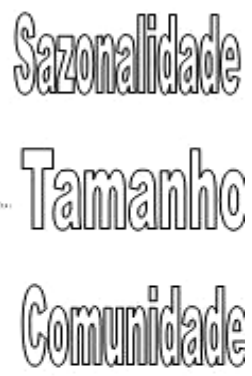

Figura 6. Fluxograma dos "sitios de repouso" de A. fulica. 


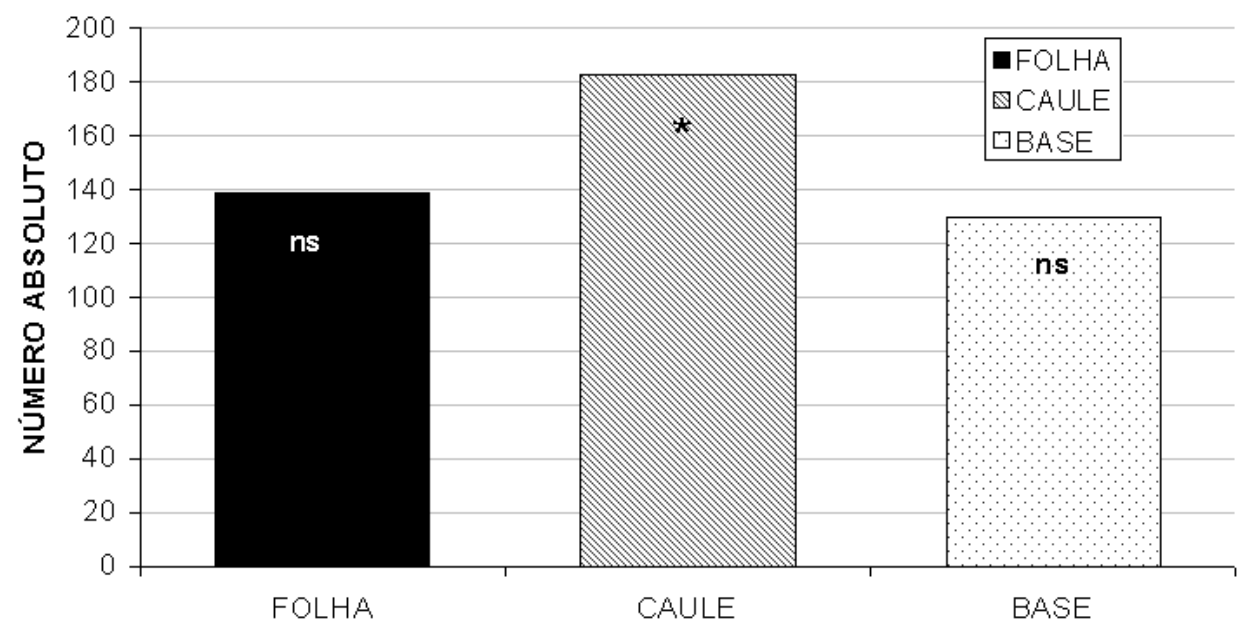

Figura 7. Numero absoluto de exemplares de A. fulica coletados na folha, caule e base de bananeira na Ilha Rasa durante o verão de 2003. Os valores foram comparados através do teste do Qui-quadrado, sendo os valores significativos $(P<0,05)$ representados pelo asterisco (*) e os não significativos representados por " $n$ s".
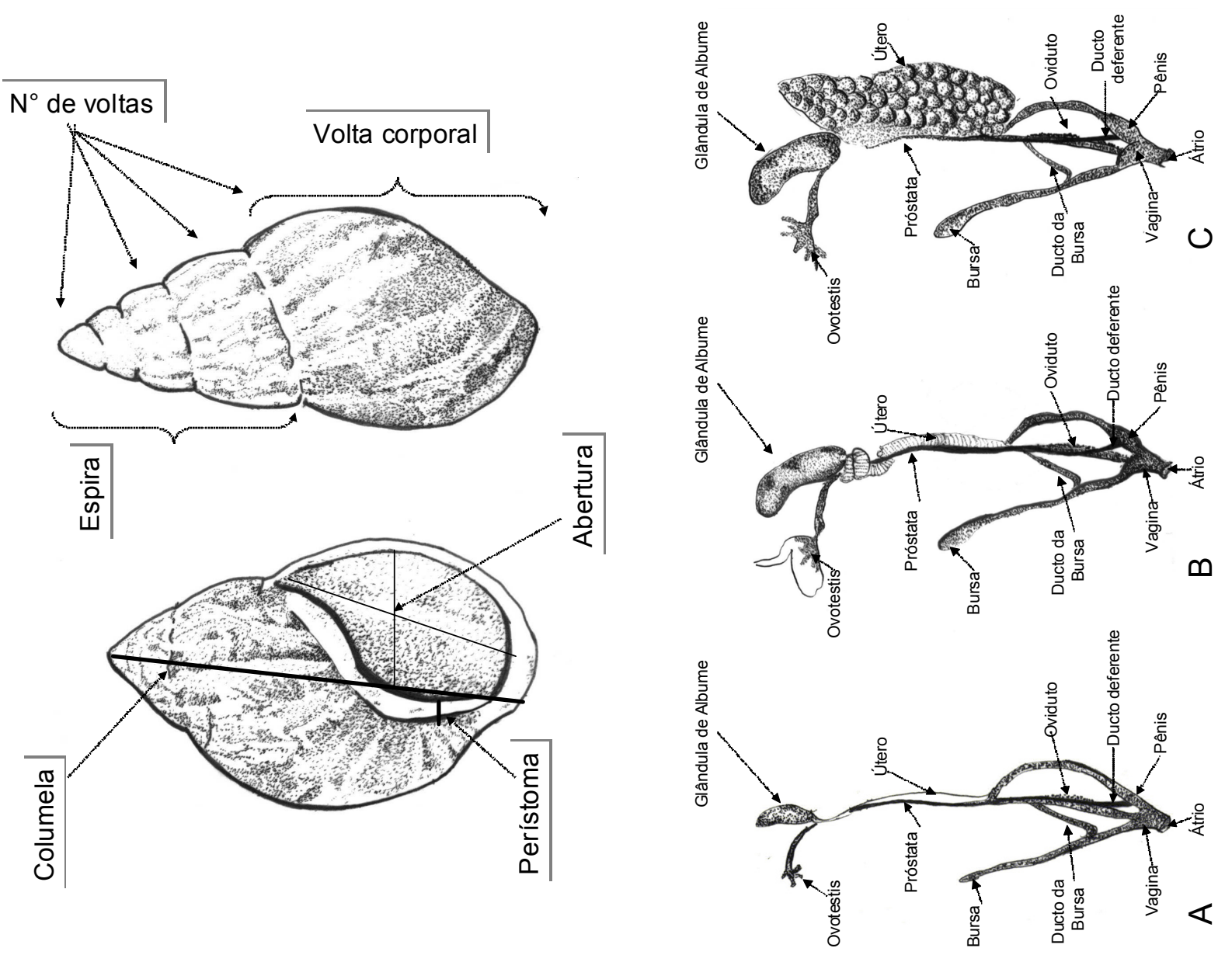

Figura 8. Estruturas da concha e do aparelho reprodutor de A. fulica (ilustração: Fischer, M. L.). 
Fischer, M.L. and Colley, E. - Biota Neotropica, v5 (n1) - BN03305012005

Tabela 1. Análise pedológica. Teor e quantidade das propriedades químicas e físicas das amostras de solo da área urbana e áreas naturais.

\begin{tabular}{lllllll}
\hline & \multicolumn{3}{c}{ Comunidades } & \multicolumn{4}{c}{ Habitats Naturais } \\
& Almeida & Ilha Rasa & Borda & Interior & Restinga & Mangue \\
\hline $\mathrm{pH}$ & 7,31 & 7,87 & 3,95 & 3,65 & 3,25 & 5,53 \\
$\mathrm{Ca}$ & 17,73 & 3,01 & 2,00 & 1,14 & 1,53 & 1,72 \\
$\mathrm{Mg}$ & 2,67 & 1,98 & 4,48 & 2,67 & 0,86 & 5,91 \\
$\mathrm{P}$ & 97,50 & 2,30 & 6,50 & 16,30 & 1,20 & 5,50 \\
$\mathrm{C}$ & 38,48 & 4,20 & 28,80 & 69,19 & 10,15 & 9,66 \\
Matéria Orgânica & 66,34 & 40 & 49,65 & 119,28 & 17,50 & 16,65 \\
AREIA\% & 7,31 & 7,87 & 85,8 & 67,4 & 94,2 & 95,5 \\
SILTE\% & 17,73 & 3,01 & 9,2 & 22,4 & 1,7 & 0,2 \\
ARGILA\% & 2,67 & 1,98 & 5,0 & 10,2 & 4,1 & 4,3 \\
\hline
\end{tabular}

Tabela 2. Plantas utilizadas como sitio de repouso pela A. fulica. As plantas acompanhadas de asterisco (*) foram relativas a registros qualitativos, por serem visualizados caramujos utilizando-a como sítio de repouso ou alimentação, porém não entraram na análise quantitativa, por não ocorrerem durante as amostragens padronizadas.

\begin{tabular}{|c|c|c|c|}
\hline Espécie & Nome popular & Origem & Utilização \\
\hline Malvaviscus arboreus Cav. data & Sapateira & América central e Meridional & $\begin{array}{l}\text { Ornamental }(\mathrm{N}= \\
56)\end{array}$ \\
\hline Dracaena fragrans & pau-d'água & África - Região do Congo & $\begin{array}{l}\text { Ornamental } \\
(\mathrm{N}=125)\end{array}$ \\
\hline Carica papaya L. & Mamão & Norte e Nordeste Brasileiro & $\begin{array}{l}\text { Alimentícia } \\
(\mathrm{N}=14)\end{array}$ \\
\hline Euphorbia cotonifolia L. & leiteiro-vermelho & América central e Meridional & $\begin{array}{l}\text { Ornamental } \\
(\mathrm{N}=4)\end{array}$ \\
\hline Hibiscus rosa-sinensis $\mathrm{L}$. & Hibisco & Ásia Tropical & $\begin{array}{l}\text { Ornamental } \\
(\mathrm{N}=19)\end{array}$ \\
\hline Manihot esculenta Crantz & Mandioca & Andes Peruanos & Alimentícia* \\
\hline Musa x paradisiaca $\mathrm{L}$. & Bananeira & Ásia & $\begin{array}{l}\text { Alimentícia }(\mathrm{N}= \\
121)\end{array}$ \\
\hline Passiflora edulis Sims. & Maracujá & América central e Meridional & $\begin{array}{l}\text { Alimentícia } \\
(\mathrm{N}=36)\end{array}$ \\
\hline Petrosilinum sativa Hoffm. & Salsinha & Cosmopolita & Alimentícia * \\
\hline Sanseviera trifasciata (De Wild.)N. E. Br. & espada-de-são-jorge & África & $\begin{array}{l}\text { Ornamental } \\
(\mathrm{N}=8)\end{array}$ \\
\hline Saccharum officinarum L. & cana-de-açúcar & Sudoeste Asiático & $\begin{array}{l}\text { Alimentícia }(\mathrm{N}= \\
\text { 7) }\end{array}$ \\
\hline Allium cepa $\mathrm{L}$. & Cebolinha & Ásia Central & Alimentícia* \\
\hline Bidens pilosa $\mathrm{L}$ & pico-pico & Cosmopolita & Nativa * \\
\hline Caladium x hortulanum Birdsey & tinhorão & Brasil & Nativa * \\
\hline Colocasia gigantea (Blume) Hook. $\mathrm{f}$. & orelha-de-elefante & Brasil & Nativa * \\
\hline Ipomoea cairica $(\mathrm{L}$.$) Sweet$ & ipoméia & Brasil & Ornamental* \\
\hline Citrus limonia (L.) Burm. F. & limoeiro & Brasil & $\begin{array}{l}\text { Alimentícia } \\
(\mathrm{N}=4)\end{array}$ \\
\hline Dioscorea $s p$ & inhame & Brasil & $\begin{array}{l}\text { Alimentícia } \\
(\mathrm{N}=5)\end{array}$ \\
\hline \multirow[t]{2}{*}{ Íris sp } & tajá & Brasil & $\begin{array}{l}\text { Alimentícia } \\
(\mathrm{N}=14)\end{array}$ \\
\hline & samambaia & Brasil & $\begin{array}{l}\text { Ornamental } \\
(\mathrm{N}=12)\end{array}$ \\
\hline Fícus luschnatiana (Miq.) Miq. & figueira & Brasil & $\begin{array}{l}\text { Nativa } \\
(\mathrm{N}=11)\end{array}$ \\
\hline Terminalia catappa & sombreiro & Brasil & $\begin{array}{l}\text { Ornamental } \\
(\mathrm{N}=5)\end{array}$ \\
\hline Schinus terebinthifolius Raddi. & aroeira & Brasil & $\begin{array}{l}\text { Nativa } \\
(\mathrm{N}=1)\end{array}$ \\
\hline Vegetação Secundária de Restinga & mato & Brasil & $\begin{array}{l}\text { Nativa } \\
(\mathrm{N}=3)\end{array}$ \\
\hline
\end{tabular}

http://www.biotaneotropica.org.br 
Tabela 3. Fauna associada ao sítio de repouso de A. fulica.

\begin{tabular}{|c|c|}
\hline Phylum & PLATHYELMINTES \\
\hline Classe & Turbellaria \\
\hline Ordem & Tricladida \\
\hline Phylum & ANNELIDA \\
\hline Classe & Hirudinea \\
\hline Classe & Oligochaeta \\
\hline Phylum & ARTHROPODA \\
\hline Classe & Chelicerata \\
\hline Subclasse & Arachnida \\
\hline Ordem & Araneae \\
\hline Ordem & Opiliones \\
\hline Subphylum & Uniramia \\
\hline Classe & Miriapoda \\
\hline Subclasse & Diplopoda \\
\hline Subclasse & Chilopoda \\
\hline Classe & Insecta \\
\hline Subclasse & Pterygota \\
\hline Ordem & Orthoptera \\
\hline Ordem & Blattodea \\
\hline Ordem & Isoptera \\
\hline Ordem & Dermaptera \\
\hline Ordem & Diptera \\
\hline Subphylum & Crustacea \\
\hline Classe & Malacostraca \\
\hline Subclasse & Eumalacostraca \\
\hline \multirow{2}{*}{ Ordem } & Decapoda \\
\hline & Metasesarma rubripes (Rathbun, 1897) \\
\hline Phylum & MOLLUSCA \\
\hline Classe & Gastropoda \\
\hline Subclasse & Gymnomorpha \\
\hline Ordem & Soleolifera \\
\hline \multirow[t]{2}{*}{ Família } & Veronicellidae \\
\hline & Vaginula boettgeri Semper, 1886 \\
\hline Subclasse & Pulmonata \\
\hline Ordem & Stylommatophora \\
\hline Superfamilia & Achatinoidea \\
\hline \multirow[t]{2}{*}{ Família } & Subulinidae \\
\hline & Subulina octona Bruguière, 1792 \\
\hline Superfamília & Limacoidea \\
\hline \multirow[t]{2}{*}{ Famila } & Limacidae \\
\hline & Deroceras sp \\
\hline Superfamíla & Strophocheiloidea \\
\hline \multirow[t]{2}{*}{ Familia } & Megalobulimidae \\
\hline & Megalobulimus parafragilior, Leme \& Indrusiak, 1990 \\
\hline Superfamília & Helicoidea \\
\hline \multirow[t]{2}{*}{ Familia } & Xantochinidae \\
\hline & Bradybaena similaris, Férussác, 1821 \\
\hline
\end{tabular}


Dados sobre a atividade da espécie parecem ser bem conhecidos, uma vez que $56,7 \%$ dos entrevistados disseram que é mais comum no verão, durante a chuva $(83,3 \%)$ e pela manhã (40\%). Quanto à alimentação, $50 \%$ afirmaram que o molusco se alimenta de plantas. Porém a maioria nunca viu se reproduzindo $(63,3 \%)$ e não houve diferenças do número de pessoas que viram e que não viram os ovos. Somente dois entrevistados disseram ver outros animais predando a A. fulica, sendo citados a cobra d'água, o pato e a galinha.

A maioria $(80 \%)$ afirmou realizar o controle populacional do molusco utilizando o sal $(80 \%)$, porém como forma de controle também foram citados o quebrar e o queimar e 13,3\% disseram não controlar.

Quando perguntado se o animal exótico causa algum problema, o número de repostas negativas e positivas foram semelhantes. As pessoas citaram como exemplos de enfermidades: câncer, feridas, meningites, cegueira, febre, doenças e vermes.

Apenas um dos entrevistados relatou que conhece alguém que come o animal, porém nenhum dos entrevistados comeu, conhece quem cria ou usa para isca.

\section{DISCUSSÃO}

Os dados do presente estudo se constituem de importantes elementos para o diagnóstico da ocupação recente de A. fulica na Ilha Rasa. A ocorrência exclusiva no ambiente antrópico e padrões diferenciais de ocupação nas comunidades de Almeida e Rasa e da estrutura populacional ao longo das estações do ano permitiram caracterizar a população da espécie exótica bem como os sítios de alimentação e repouso e a fauna associada. A análise etnoecológica do conhecimento da comunidade a respeito do caramujo foi fundamental para a subsidiar as propostas de manejo.

A ocorrência exclusiva de A. fulica no ambiente antrópico pode ser relacionada a dois fatores: preferência por áreas alteradas e o aparecimento recente da espécie na ilha.

A preferência por ambientes alterados tem sido registrada por vários autores em diferentes países (Lake \& O'dowd 1991, Escabarssiere \& Moreno 1997; Teles et al. 1997, Teles \& Fontes 2002, Simberloff 2003), inclusive na região de endemismo, Ilha Mauricius (Craze \& Mauremootoo 2002). A espécie $A$. fulica representa um típico animal do grupo r-estrategista, uma vez que, ocupa ambiente alterado, apresenta grande resistência a fatores abióticos, é um bom competidor e como estratégia reprodutiva deposita muitos ovos de pequeno tamanho, com pouca alocação de energia e baixa expectativa de sobrevivência. De forma geral esses padrões são apresentados por espécies invasoras (Escabarssiere \& Moreno 1997).

A suposição de que o aparecimento da população de A. fulica na Ilha Rasa é recente pode ser atestada por três evidências. A primeira está relacionada com a estimativa de que haja poucos indivíduos na Ilha (cerca de 9.000). Esse número é bem menor do que o estimado para o município de Pontal do Paraná (cerca de 403.000) (Simião 2003) e para Guaraqueçaba sede (63.000) (Fischer, dado não publicado). Civeyrel \& Simberloff (1996) fizeram uma compilação das estimativas presentes na literatura, dos lugares mais problemáticos como Ilha de Martinica (retirados $200.000 \mathrm{em}$ um ano), Nova Caledônia (9 anos depois da introdução: $400 \mathrm{~kg} / \mathrm{ha})$, Ilhas Maldivas $\left(72,6 / \mathrm{m}^{2}\right)$, Ilhas Filipinas (coletados 45 milhões em 1.600/ha, em 7 meses) e Ilhas Christimans $\left(10 / \mathrm{m}^{2}\right)$. Segundo Craze \& Mauremootoo (2002), a estimativa do tamanho da população e suas características locais são o primeiro passo para qualquer plano de manejo.

A segunda evidência foi baseada em relatos dos moradores durante a análise etnoecológica. Segundo os ilhéus, os animais estão na ilha a pouco mais de um ano e são originários de duas matrizes que foi levada de Paranaguá por uma moradora. Santos et al. (2002), também fizeram um relato de uma população recente de A. fulica em Angras dos Reis, baseando-se em relatos dos moradores, evidenciando que a comunidade é uma fonte importante de informações para compreensão da dimensão do problema. No entanto, deve-se considerar a possibilidade de perceberem o problema apenas quando se torna evidente, ou seja, a população do invasor esteja instalada ou em decorrência de campanhas de sensibilização em cartazes, rádio e televisão.

A terceira evidência é a ausência dos caramujos na natureza, que pode ser interpretada baseando-se em três hipóteses. Na primeira hipótese, pode-se acreditar que o ambiente natural, característico de Mata Atlântica, por ser diferente da região de origem, não apresenta condições físicas ou biológicas para o estabelecimento da espécie invasora. No entanto, ao assumir essa hipótese é importante considerar que em outros locais o caramujo africano ocupa matas nativas, como no Havaí, em que estabeleceu uma grande população em ambiente natural (Lay et al. 1982).

A segunda hipótese é que na mata nativa haja algum controlador biológico que impeça a entrada e estabelecimento de $A$. fulica. Os ilhéus relataram terem visto a espécie sendo predada pela cobra d'água e no ambiente urbano pelo pato e pela galinha. Em várias situações foi registrada a planária terrestre consumindo o caramujo exótico, no entanto sua efetividade como regulador da população de $A$. fulica deve ser estudada mais detalhadamente. De maneira semelhante com o que ocorre na Ilha Rasa, nas Ilhas Christmas Lake \& O’Dowd (1991) observaram que a $A$. fulica ocorre apenas na área urbana, não colonizando a mata nativa. Os autores verificaram que a entrada da espécie exótica no interior da mata é impedida pela presença do caranguejo nativo Gecarcoidea natalis, Pocock. Esse animal compete principalmente com o caramujo pelo habitat de serrapilheira, onde ambos usam como refúgio e alimento, porém o caranguejo também preda o caramujo. 
A terceira hipótese preconiza que a espécie invasora não ocupou o ambiente nativo, devido a ter espaço no ambiente antrópico, o seu preferido, porém que a partir do momento que houver poucos recursos de refúgio e alimento, elas passarão a usar também a floresta. Essa hipótese é apoiada na evidência de que enquanto em alguns terrenos são coletados números elevadíssimos de caramujos, em outros ainda há substratos livres. Segundo Civeyrel \& Simberloff (1996), a população de $A$. fulica passa por três fases durante seu estabelecimento, a primeira é de crescimento exponencial, determinada por indivíduos grandes e vigorosos; a segunda trata do estabelecimento da população com duração variável e a terceira é a fase de declínio caracterizada por uma população de pequenos indivíduos.

A quantificação do caramujo africano nas bananeiras é outra evidência de que ainda existem muitos substratos em potencial para ocupação do caramujo, enquanto em algumas árvores foram encontrados mais de 40 animais, muitas não havia nenhum. A. fulica apresenta capacidade de estabelecer uma grande população em diferentes ambientes nos países onde foi introduzida (Lake \& O’Dowd 1991, Civeyrel \& Simberloff 1996, Cowie \& Robinson 2003, Simião 2003).

O padrão diferencial nas características das populações de $A$. fulica em Almeida e Rasa, também foram registrados na Ilha Samoa e Samoa Americana (Cowie \& Robinson 2003), ilustrando bem que o potencial para uma espécie invasora é uma soma de características da espécie e das condições ambientais e estruturais para sua instalação e posterior dispersão.

O predomínio da espécie em Almeida pode ser justificado principalmente pela maior presença de substratos utilizados como sítio de repouso e alimentação. Esses sítios de refúgio e alimentação são caracterizados principalmente por plantas exóticas (ornamentais e alimentícias). A mesma evidência foi feita em outros locais em que $A$. fulica foi introduzida (Mead 1950, Lake \& O’Dowd 1991, Escabarssiere \& Moreno 1997, Teles et al. 1997, Teles \& Fontes 2002, Craze \& Mauremootoo 2002, Simberloff 2003). Segundo Raut \& Barker (2002), a disponibilidade de plantas e preferência alimentar podem ter efeitos importantes na dinâmica da população, regulando a taxa de crescimento e efeito na sobrevivência, fecundidade e recrutamento.

A ausência de coleta pública de lixo e o pequeno tamanho da Ilha somada ao fato de ser área de proteção ambiental fazem com que os ilhéus busquem alternativas pouco indicadas para seu lixo. Eles queimam, enterram, jogam no mar ou embaixo das plantas usadas como cercas-vivas. Assim se torna outro sítio de refúgio importante, característico da comunidade de Almeida. A espécie invasora pode também usar esses resíduos como alimento, consumindo inclusive papéis e plásticos (Teles \& Fontes 2002, Simião 2003).
A diferença entre a composição química e física do solo, aliada principalmente à deposição de lixo, contribuíram com o aumento da matéria orgânica, caracterizando o solo da comunidade de Almeida como um substrato mais favorável ao desenvolvimento dos indivíduos de A. fulica e ao estabelecimento de sua população. Ainda, deve-se considerar que em Almeida há imensos afloramentos de sambaqui, onde freqüentemente é possível ver o molusco invasor ingerindo as valvas das conchas, contribuindo para a degradação dessa formação que já está sendo perdida em decorrência da ocupação humana. Pacheco et al. (1998) testaram o desempenho de $A$. fulica em diferentes tipos de solos e observaram que a evolução do ganho de peso e crescimento (comprimento e largura) apresentou melhores resultados no tratamento Latossol vermelho com alto teor de areia, o qual apresenta composição semelhante ao solo de Almeida. Segundo Raut \& Barker (2002), A fulica pode usar diferentes tipos de solos como refúgio e para retirada de nutrientes, porém irá refletir quantitativamente e qualitativamente na taxa de crescimento, tamanho, peso, forma da concha e coloração. Sendo especialmente importante para os juvenis.

A diferença sazonal, evidente entre as dimensões e espaçamento de $A$. fulica, leva a suposição que a espécie apresenta um ciclo sazonal com uma ou duas gerações por ano. Provavelmente a cópula ocorra principalmente durante a primavera e o outono, uma vez que a ocorrência dos maiores indivíduos na primavera poderiam estar representando a presença de adultos, o menor espaçamento, a interação intraespecífica e a menor altura, a possibilidade uma maior chance de ocorrerem cópulas no solo. A evidência de sazonalidade de A. fulica foi registrada por Lay et al. (1982) que relatam a dispersão de $A$. fulica durante o ano todo, porém é particularmente evidente durante ou após o inverno. Raut \& Barker (2002), também considera a sazonalidade, desde que os ciclos estejam relacionados com a disponibilidade de períodos favoráveis. Os autores relatam, ainda, que em algumas regiões onde se tornou invasora, pode ocorrer dois picos pronunciados em cada estação. $\mathrm{O}$ primeiro seria logo após a retomada de atividade e finalização da fase de estivação e a segunda 2 a 3 meses mais tarde. Dados esses que corroboram com o padrão observado na Ilha Rasa. Berry \& Chan (1968) também consideram a existência de um aparente ciclo anual de $A$. fulica na Malásia (continente asiático), porém relacionado às estações secas e chuvosas, sendo as taxas reprodutivas influenciadas por fatores internos (provavelmente hormônios) e fatores ambientais e comprimento dos dias.

Acredita-se que na Ilha Rasa $A$. fulica pode se reproduzir durante todo o ano, pois foram encontrados indivíduos adultos e posturas de ovos. Porém, a existência de uma geração no outono, além da primavera, pode ser fundamentada pelos dados de Raut \& Chose (1982) que verificaram que $A$. fulica pode manter o esperma retido na 
bursa por mais de 100 dias durante o período de estivação. O que fundamentaria a existência da cópula no outono, passagem do inverno em estivação, e deposição dos ovos na primavera.

O menor tamanho de exemplares da A. fulica e o grande espaçamento registrado durante o outono levam a suposição que neste período esteja ocorrendo a dispersão, preferencialmente no período que antecede o inverno, estação mais fria e seca. Segundo Tomiyama (1992), os caramujos jovens não são territoriais e se deslocam em grandes distâncias mudando o sítio de repouso, enquanto os adultos são aparentemente territoriais. Nesses animais, já podem ser observadas nitidamente as estruturas do sistema reprodutor na porção masculina que viabilizariam a cópula com animais grandes, territoriais que tenham desenvolvido também a porção feminina.

No presente estudo o menor tamanho de um animal que realizou postura foi de $3,4 \mathrm{~cm}$ de comprimento de concha e $0,04 \mathrm{~cm}$ de espessura do perístoma. Esses dados são confrontantes com os de Tomiyama (2002), o qual afirma que a espécie torna-se madura sexualmente quando o perístoma mede $0,05 \mathrm{~cm}$. Segundo o autor, a partir do desenvolvimento do aparelho reprodutor feminino não há mais crescimento de concha.

O estado de estivação de $A$. fulica acompanhado da formação de epifragma durante o inverno, caracteriza uma das principais estratégias de sucesso de sobrevivência e ocupação da espécie nos diversos ambientes. A razão pela qual $A$. fulica entra em estivação é a mesma que os demais gastrópodes estilomatóforos, uma vez que as condições ambientais se tornam desfavoráveis o caramujo seleciona um local protegido, se retrai no interior da concha e a fecha com o epifragma. O epifragma vai sendo formado a partir do perístoma, sendo composto basicamente de carbonato de cálcio. Dessa forma, diminuem a exposição da área do corpo sujeita a evaporação e às atividades fisiológicas, garantindo a manutenção das reservas energéticas e da água corporal em níveis compatíveis a sua sobrevivência (Raut \& Chose, 1982; Struthers et al., 2002; D’Ávila, et al., 2004).

Na composição da fauna associada ao sítio de repouso de $A$. fulica, destaca-se o caramujo gigante endêmico ameaçado de extinção $M$. parafragilior. Segundo os ilhéus, esses animais eram freqüentes, porém têm se tornado cada vez mais raros. É possível que apesar de ser endêmico e habitar as áreas naturais esteja sofrendo pressão da competição com A. fulica por espaço e alimento na área urbana, uma vez que, foi encontrado preferencialmente na base de plantas frutíferas. Segundo Santos et al. (2002), o risco da perda da biodiversidade aumenta com a falta de conhecimento sobre a malacofauna endêmica insular brasileira e a relação com os moluscos exóticos, o que já ocorre em outros países onde A. fulica foi introduzida (Civeyrel \& Simberloff 1996, Cowie \& Robinson 2003).
A análise etnoecológica é uma ferramenta importante em um plano de manejo, pois a ocorrência associada ao ambiente antrópico, remete que os principais elementos dessa ação serão os moradores que irão controlar e manter um ambiente pouco favorável para instalação da espécie. $\mathrm{Na}$ Ilha Rasa apesar das pessoas reconhecerem a $A$. fulica como um caramujo exótico, distinguirem do caramujo endêmico $M$. parafragilior e revelar dados corretos a respeito da sua biologia e ecologia, mostraram dados muito fantasiosos a respeito dos agravos da saúde causados pelo caramujo. Elucidando que esse é um ponto principal que deve ser trabalhado. A sensibilidade a respeito dos aspectos de história natural da espécie diferiu dos dados de Simião (2003) em Pontal do Paraná, em que as pessoas percebiam o animal por ser evidente, mas não mostravam interesse em entender sua biologia e problemática.

A presença evidente de $A$. fulica nas comunidades e o transtorno causado pelo caramujo que devora as cercasvivas, plantas ornamentais e alimentícias, e a ameaça à saúde humana, não são dados suficientes para sensibilizar as pessoas, uma vez que poucos moradores se dispõem a contribuir com o manejo da espécie na ilha. A proposta informal feita aos ilhéus para o controle e prevenção da ocupação pelo caramujo foi que fossem retiradas as plantas exóticas utilizadas como cercas-vivas, a manutenção dos quintais limpos, a utilização de composteira ecologicamente correta e a catação dos caramujos. No entanto, fatores como características culturais, falta de alternativa para delimitar os terrenos e descarte de lixo mostrou ser fundamental para o impedimento do trabalho de erradicação do molusco na ilha. Poucos locais do mundo conseguiram erradicar a $A$. fulica depois que ela se estabeleceu (Escarbassiere \& Moreno 2002). Um dos raros casos de sucesso foi registrado para Miame, onde uma população recente ( 3 anos) presente em 42 quadras, foi erradicada depois de sete anos de catação por profissionais capacitados, uso de iscas com veneno e muita campanha educativa que renderam um investimento de mais de um milhão de dólares (Simberloff 2003).

Os dados do presente estudo sugerem que a população de $A$. fulica na Ilha Rasa representa uma população recentemente introduzida em fase de estabelecimento, para então se dispersar. Sendo então, esse o melhor momento para ações de erradicação. Padrões culturais e estruturais divergentes entre as duas comunidades avaliadas representam bem que as condições físicas são importantes para o estabelecimento da espécie invasora. A retirada das cercas-vivas compostas por espécies exóticas, acarretaria na diminuição de sítios de repouso, de alimentação e de posturas que ocorrem em pelo menos duas fases anuais. Programas de sensibilização da comunidade tanto com relação à espécie invasora quanto ao manejo do lixo são importantes. O conhecimento dos reais problemas de saúde, ambientais e econômicos e a consciência do seu papel como principal elemento na conservação do ambiente 
natural no qual está inserido é o passo inicial. A comunidade deve estar atenta à importância de todas as espécies na manutenção dos ambientes naturais. A coleta do lixo é uma das questões de infra-estrutura que deve ser urgentemente tratada e discutida com as autoridades, pois além de proporcionar a instalação desta e de outras espécies exóticas traz sérios problemas ambientais e de saúde. O diagnóstico da estrutura da população e como está usando o ambiente disponível ao longo do ano, ressalta a importância no monitoramento ambiental durante e após a ação de controle e manejo. Esse estudo também é um importante subsídio para estudos em outras regiões, porém o manejo deve ser adequado para cada realidade e para que seja efetivo, é extremamente importante um diagnóstico prévio.

\section{Agradecimentos}

A pró-reitoria de pesquisa e pós-graduação da PUCPR pela concessão da Bolsa de PIBIC/PUCPR e apoio logístico, Á Sociedade de Pesquisa em Vida Selvagem (SPVS) pelo apoio logístico; Dr ${ }^{\mathrm{a}}$ Leny C. M. Costa, Dr ${ }^{\mathrm{a}}$ Norma Campos Salgado, Bióloga Gisélia Rubio, Msc. Andréia Isac, aos graduandos Nicole M. Latoski, Ana Paula Winter, Lucimara Fabrício e Nicholas Kaminski, e aos moradores da Ilha rasa.

\section{Referências Bibliográficas}

ALOWE, S, BROWNE, M, BOUDJELAS, S. 2004. 100 of the world's worst invasive alien species. A selection from the global invasive species database. Disponível em www.issg.org/database [2004].

BERRY, A.J \& CHAN, L.C. 1968. Reproductive condition and tentacle extirpation in Malayan Achatina fulica (Pulmonata). Aust. J. Zoo., 16: 849-855.

CIVEYREL, L \& SIMBERLOFF, D. 1996. A tale of two snails: is the cure worse than the disease? Biodiversity and Conservation, 5: 1231-1252.

COWIE, R. H. 1998. Patterns of introduction of non-indigenous non-marine snails and slugs in the Hawaiian Islands. Biodiversity and Conservation, 7: 349-368. http://hbs.bishopmuseum.org/pdf/Cowie-1998.pdf

COWIE, R. H. 2001. Can snails ever be effective and safe biocontrol agents? International Journal of pest management. 47: 23 - 40. http://www.institutohorus.org.br/ download/artigos/Cowie\%202001.pdf

COWIE, R.H \& ROBINSON, A.C. 2003. The decline of native Pacific island faunas: change in status of the land snail of Samoa through the 20th centry. Biological Conservation, 110: $55-65$.

CRAZE, P.D. \& MAUREMOOTOO, J.R. 2002. A test of methods for estimating population size of the invasive land snail Achatina fulica in dense vegetation. Journal of Applied Ecology, 39: 653 - 660.
D’ÁVILA, S., DIAS, RJP, BESSA, L.C.A., DAEMON, E. 2004. Resistência a dessecação em três espécies de moluscos terrestres: aspectos adaptativos e significativos para o controle de helmintos. Rev. Bras. Zoociências Juiz de fora, 6: 115 - 127. http://www.comportamento.ufjf.br/ revista10.htm

ESCARBASSIERE, R.M\& MORENO, E.M. 1997. Nota acerca de la Achatina (LISSAACHATINA) fulica (BOWDICH, 1822) peligroso caracol africano (PULMONATAACHATINIDAE) introducido en Venezuela. Acta Biol. Venz. 17: 37-40.

KOSLOSKI, M.A \& FISCHER, M.L. 2002. Primeira ocorrência de Achatina fulica (Bowdich, 1822) no litoral do Estado do Paraná (Mollusca; Stylommatophora; Achatinidae). Estudos de Biologia, 24: 65 - 69

LAKE, P \& O'DOWD, D. 1991. Red crabs in rain forest, Christmans Island: biotic resistance to invasion by an exotic snail. Oikos, 62: 25-29.

LAY, P.Y, FUNASAKY, S.Y \& HIGA, S.Y. 1982. Introduction for biological control in Hawaii: 1979 and 1980. Hawaiian Entomological Society, 24: 109- 111.

LEME, J. L. M \& INDRUSIAK, L. F. 1990. Megalobulimus parafragilior. SP. N., uma nova espécie de Pulmonata terrestre da serra do mar (Gastropoda, Megalobulimidae). Papeis Avulsos Zool. 5: 97-105.

MEAD, A.R. 1950. Comparative genital anatomy of some African Achatinidae (Pulmonata). Bulletin: Museum of Comparative Zoology. 105: 219-291.

MINISTÉRIO DO MEIO AMBIENTE(MMA).2003. Lista das Espécies da Fauna Brasileira Ameaçada de Extinção. Instrução Normativa $n^{\circ}$ 3, de 27 de maio de 2003, do Ministério do Meio Ambiente. Disponível: http:// www.ibama.gov.br/fauna/downloads/lista\%20spp.pdf [27 mai. 2003]

PACHECO, P. MARTINS, M.F., LUCHESI, M., RIBEIRO, S.A., SPERS, A. RODRIGUES, P.H.M. 1998. Estudo do desempenho do escargot Achatina fulica em diferentes tipos de solo. Arq. Inst. Biol., 65: 9 - 14.

RAUT, S.K \& CHOSE, K.C. 1982. Viability of sperms in aestivating Achatina fulica Bowdich and Macrochlamys indica Godwin-Austen. Journal of Molluscs Studies. 48: 87-94.

RAUT, K \& BARKER, G. 2002. Achatina fulica Bowdich and others Achatinidae pest in tropical agriculture in Mollusks as crop pest (Barker \& Hamilton eds). New Zealand: CAB Publishing.

SANTOS, S.B, MONTEIRO, D.P, THIENGO, S.C. 2002. Achatina fulica (MOLLUSCA, ACHATINIDAE) na Ilha Grande, Angra dos Reis, Rio de Janeiro: implicações para saúde ambiental. Biociências, 10: 159-152. 
SIMBERLOFF, D. 2003. How much information on population biology is needed to manage introduced species? Conservation Biology, 17: 83 - 92.

SIMIÃO, M.S. 2003. Estimativa populacional e caracterização da população de Achatina fulica Bowdich, 1822 (Mollusca; Achatinidae) no município de Pontal do Paraná, Paraná, Brasil. Trabalho de conclusão de Curso de Biologia da Pontifícia Universidade Católica do Paraná.

SPVS - Sociedade de Pesquisa e Proteção da Vida Selvagem e Educação Ambiental. 1999. Projeto saúde comunitária, educação e conservação para a região de Guaraqueçaba, Paraná, Brasil. Relatório anual da Sociedade de Pesquisa em vida Selvagem e Educação Ambiental.

STRUTHERS, M. ROSAIR, G, BUCKMAN,J. VINEY,C. 2002. The physical and chemical microstructure of the Achatina fulica epiphragm. Journal of Molluscan Studies, 68: 165- 171 .

TELES, H.M.S. VAZ, J.F, FONTES, L.R., DOMINGOS, M.F. 1997. Registro de Achatina fulica Bowdich, 1822 (Mollusca, Gastropoda) no Brasil: caramujo hospedeiro intermediário de Angiostrongilíase. Revista de Saúde Pública, 31: 310-312. http://www.scielosp.org/pdf/rsp/ v31n3/2294.pdf

TELES, H.M.S \& FONTES, L.R. 2002. Implicações da introdução e dispersão de Achatina fulica Bowdich, 1882 no Brasil. Boletim do Instituto Adolfo Lutz, 12: 3 - 5.

TOMIYAMA, K. 1992. Homing behavior of the giant African snail Achatina fulica (Ferussac) (Gastropoda: Pulmonata). Journal Ethology, 10: 139-47.

TOMIYAMA, K. 1993. Growth and maturation pattern in the African giant snail, Achatina fulica (Férussac) (Stylommatophora: Achatinidae). Venus, 52: 87-100.

TOMIYAMA, K. 2000. Daily dispersal from resting sites of the African giant snail, Achatina fulica (Férussac) (Pulmonata; Achatinidae), on a North Pacific Island. Tropics, 10: $243-249$.

TOMIYAMA, K. 2002. Age dependency of sexual role and reproductive ecology in a simultaneously hermaphroditic land snail, Achatina fulica (Stylommatophora: Achatinidae). Venus-Tokyo, 60:273 - 283.

VASCONCELLOS, M.C \& PILE, E. 2001. Ocorrência de Achatina fulica no Vale do Paraíba, Estado do Rio de Janeiro, Brasil. Rev. Saúde Pública 35: 582-584. h t t p : / / w w w . s c i e 1 o s p . o r g / scielo.php?script $=$ sci_arttext $\&$ pid $=$ S 0034 89102001000600013
Título: Espécie invasora em reservas naturais: caracterização da população de Achatina fulica Bowdich, 1822 (Mollusca - Achatinidae) na Ilha Rasa, Guaraqueçaba, Paraná, Brasil

Autores: Marta Luciane Fischer \& Eduardo Colley

Biota Neotropica, Vol. 5 ( number 1): 2005

http://www.biotaneotropica.org.br/v5 n 1/pt/ abstract?article+BN03305012005

Recebido em 13/10/04

Recebida em 31/01/05

Publicado em 07/03/05 
ANEXO 1. Tamanho médio das estruturas da concha e do sistema reprodutor de A. fulica, nas quatro estações do ano (média \pm desvio padrão, amostra e intervalo de variação). As médias foram testadas pelo teste Kruskall-Wallis, sendo os valores estatisticamente diferentes $(P<0,05)$, representados por letras distintas. Correção entre as estruturas da concha e do aparelho reprodutor. Correlação (*) significativa entre as estruturas da concha e do aparelho reprodutor. A relação entre as partes da concha e estruturas do sistema reprodutor com a estação do ano evidenciou que o lábio e abertura da concha, e bursa e pênis apresentaram variações durante o ano. A relação entre as estruturas do sistema reprodutor e a concha evidenciou a relação da próstata, bursa e pênis com a maioria das demais estruturas.

\begin{tabular}{|c|c|c|c|c|c|}
\hline Estrutura & Primavera & Verão & Outono & Inverno & Correlação * \\
\hline Columela & $\begin{array}{c}6,4 \pm 1,5 \\
(90 ; 36-99) a\end{array}$ & $\begin{array}{c}6 \pm 1,2 \\
(90 ; 4,4-9,7) a\end{array}$ & $\begin{array}{c}6,8 \pm 1,9 \\
(90 ; 4-10,7) a\end{array}$ & $\begin{array}{c}6,3 \pm 1,3 \\
(90 ; 4,7-10,6) a\end{array}$ & $\begin{array}{l}\text { Glândula - } \mathrm{r}^{2}=0,1 ; \mathrm{P}<0,01 \\
\text { Próstata - } \mathrm{r}^{2}=0,2 ; \mathrm{P}<0,01 \\
\text { Bursa - } \mathrm{r}^{2}=0,1 ; \mathrm{P}<0,01 \\
\text { Pênis - } \mathrm{r}^{2}=0,3 ; \mathrm{P}<0,01\end{array}$ \\
\hline Abertura & $\begin{array}{c}3,2 \cdot 0,6 \\
(90 ; 1,9-46) a\end{array}$ & $\begin{array}{c}3,1 \pm 0,5 \\
(90 ; 2,4-4,3) a\end{array}$ & $\begin{array}{c}3,4 \pm 0,7 \\
(90 ; 2,3-4,8) b\end{array}$ & $\begin{array}{c}3,2 \pm 0,5 \\
(90 ; 2,2-4,9) a\end{array}$ & $\begin{array}{l}\text { Glândula }-\mathrm{r}^{2}=0,06 ; \mathrm{P}<0,01 \\
\text { Próstata }-\mathrm{r}^{2}=0,2 ; \mathrm{P}<0,01 \\
\text { Bursa - } \mathrm{r}^{2}=0,1 ; \mathrm{P}<0,01 \\
\text { Pênis - } \mathrm{r}^{2}=0,3 ; \mathrm{P}<0,01\end{array}$ \\
\hline Espira & $\begin{array}{c}3,3 \pm 3,9 \\
(90 ; 1,9-1,8) a\end{array}$ & $\begin{array}{c}3,2 \pm 0,8 \\
(90 ; 2,2-7,0) a\end{array}$ & $\begin{array}{c}3,6 \pm 1,3 \\
(90 ; 2,0-8,0) b\end{array}$ & $\begin{array}{c}3,4 \pm 0,8 \\
(90 ; 1,7-5,9) a\end{array}$ & $\begin{array}{l}\text { Glândula }-\mathrm{r}^{2}=0,03 ; \mathrm{P}<0,01 \\
\text { Próstata - } \mathrm{r}^{2}=0,1 ; \mathrm{P}<0,01 \\
\text { Bursa - } \mathrm{r}^{2}=0,1 ; \mathrm{P}<0,01 \\
\text { Pênis - } \mathrm{r}^{2}=0,3 ; \mathrm{P}<0,01\end{array}$ \\
\hline Voltas & $\begin{array}{c}6,6 \pm 0,9 \\
(90 ; 6-8) a\end{array}$ & $\begin{array}{c}6,8 \pm 0,8 \\
(90 ; 4-8) a\end{array}$ & $\begin{array}{c}6,9 \pm 0,7 \\
(90 ; 6-8) a\end{array}$ & $\begin{array}{c}6,6 \pm 0,9 \\
(90 ; 5-8) a\end{array}$ & $\begin{array}{l}\text { Próstata - } \mathrm{r}^{2}=0,03 ; \mathrm{P}<0,01 \\
\text { Bursa - } \mathrm{r}^{2}=0,02 ; \mathrm{P}<0,01 \\
\text { Pênis - } \mathrm{r}^{2}=0,1 ; \mathrm{P}<0,01\end{array}$ \\
\hline Perístoma & $\begin{array}{c}0,4 \pm 0,2 \\
(90 ; 0,1-0,9) a\end{array}$ & $\begin{array}{c}0,3 \pm 0,1 \\
(90 ; 0,2-0,5) b\end{array}$ & $\begin{array}{c}0,3 \pm 0,2 \\
(90 ; 0,2-0,9) \mathrm{ab}\end{array}$ & $\begin{array}{c}0,4 \pm 0,5 \\
(90 ; 0,2-0,4) a\end{array}$ & $\begin{array}{l}\text { Próstata - } \mathrm{r}^{2}=0,02 ; \mathrm{P}<0,01 \\
\text { Bursa - } \mathrm{r}^{2}=0,01 ; \mathrm{P}<0,01 \\
\text { Pênis - } \mathrm{r}^{2}=0,1 ; \mathrm{P}<0,01\end{array}$ \\
\hline Glândula & $\begin{array}{c}1,0 \pm 1,7 \\
(90 ; 0,003-7,6) a\end{array}$ & $\begin{array}{c}0,7 \pm 0,9 \\
(90 ; 0,001-0,4) a\end{array}$ & $\begin{array}{c}0,5 \pm 1,2 \\
(90 ; 0,002-0,8) a\end{array}$ & $\begin{array}{c}0,7 \pm 2,2 \\
(90 ; 0,003-19) a\end{array}$ & $\begin{array}{l}\text { Próstata - } \mathrm{r}^{2}=0,1 ; \mathrm{P}<0,01 \\
\text { Bursa - } \mathrm{r}^{2}=0,03 ; \mathrm{P}<0,01 \\
\text { Pênis - } \mathrm{r}^{2}=0,1 ; \mathrm{P}<0,01 \\
\text { Columela }-\mathrm{r}^{2}=0,1 ; \mathrm{P}<0,01 \\
\text { Abertura - } \mathrm{r}^{2}=0,06 ; \mathrm{P}<0,01 \\
\text { Espira - } \mathrm{r}^{2}=0,03 ; \mathrm{P}<0,01\end{array}$ \\
\hline Próstata & $\begin{array}{c}1,1 \pm 2,1 \\
(90 ; 0,04-16) a\end{array}$ & $\begin{array}{c}1,1 \pm 1 \\
(90 ; 0,1-5,3) a\end{array}$ & $\begin{array}{c}1,45 \pm 2,2 \\
(90 ; 0,1-17,3) a\end{array}$ & $\begin{array}{c}1,1 \pm 1,5 \\
(90 ; 0,04-13) a\end{array}$ & $\begin{array}{l}\text { Columela - } \mathrm{r}^{2}=0,2 ; \mathrm{P}<0,01 \\
\text { Glândula - } \mathrm{r}^{2}=0,1 ; \mathrm{P}<0,01 \\
\text { Perístoma - } \mathrm{r}^{2}=0,02 ; \mathrm{P}<0,01 \\
\text { Voltas - } \mathrm{r}^{2}=0,03 ; \mathrm{P}<0,01 \\
\text { Abertura - } \mathrm{r}^{2}=0,2 ; \mathrm{P}<0,01 \\
\text { Espira - } \mathrm{r}^{2}=0,1 ; \mathrm{P}<0,01 \\
\text { Bursa - } \mathrm{r}^{2}=0,1 ; \mathrm{P}<0,01 \\
\text { Pênis - } \mathrm{r}^{2}=0,2 ; \mathrm{P}<0,01\end{array}$ \\
\hline Bursa & $\begin{array}{c}0,1 \pm 0,2 \\
(90 ; 0,01-0,80) a\end{array}$ & $\begin{array}{c}0,1 \pm 0,2 \\
(90 ; 0,01-1,7) a\end{array}$ & $\begin{array}{c}0,2 \pm 0,23 \\
(90 ; 0,002-1,2) b\end{array}$ & $\begin{array}{c}0,2 \pm 0,3 \\
(90 ; 0,01-2) a\end{array}$ & $\begin{array}{l}\text { Columela }-\mathrm{r}^{2}=0,1 ; \mathrm{P}<0,01 \\
\text { Glândula - } \mathrm{r}^{2}=0,03 ; \mathrm{P}<0,01 \\
\text { Perístoma - } \mathrm{r}^{2}=0,1 ; \mathrm{P}<0,01 \\
\text { Voltas - } \mathrm{r}^{2}=0,02 ; \mathrm{P}<0,01 \\
\text { Abertura - } \mathrm{r}^{2}=0,1 ; \mathrm{P}<0,01 \\
\text { Espira - } \mathrm{r}^{2}=0,1 ; \mathrm{P}<0,01 \\
\text { Pênis - } \mathrm{r}^{2}=0,2 ; \mathrm{P}<0,01\end{array}$ \\
\hline Pênis & $\begin{array}{c}0,9 \pm 0,5 \\
(90 ; 0,2-2,4) a\end{array}$ & $\begin{array}{c}0,8 \pm 0,4 \\
(90 ; 0,2-1,9) a\end{array}$ & $\begin{array}{c}0,7 \pm 0,4 \\
(90 ; 0,1-1,7) b\end{array}$ & $\begin{array}{c}0,8 \pm 0,4 \\
(90 ; 0,2-1,5) a\end{array}$ & $\begin{array}{l}\text { Columela - } \mathrm{r}^{2}=0,3 ; \mathrm{P}<0,01 \\
\text { Glândula }-\mathrm{r}^{2}=0,1 ; \mathrm{P}<0,01 \\
\text { Perístoma }-\mathrm{r}^{2}=0,1 ; \mathrm{P}<0,01 \\
\text { Voltas - } \mathrm{r}^{2}=0,1 ; \mathrm{P}<0,01 \\
\text { Abertura - } \mathrm{r}^{2}=0,3 ; \mathrm{P}<0,01 \\
\text { Espira - } \mathrm{r}^{2}=0,3 ; \mathrm{P}<0,01 \\
\text { Próstata - } \mathrm{r}^{2}=0,2 ; \mathrm{P}<0,01 \\
\text { Bursa - } \mathrm{r}^{2}=0,2 ; \mathrm{P}<0,01\end{array}$ \\
\hline
\end{tabular}

